\title{
Global Trends in Urban Electricity Demands for Cooling and Heating
}

Michael Waite ${ }^{1}$, Elliot Cohen 2 , Henri Torbey, Michael Piccirilli3 ${ }^{3}$ Yu Tian ${ }^{4}$, Vijay Modi ${ }^{1}$ ${ }_{1}^{1}$ Department of Mechanical Engineering, Columbia University, New York, NY, USA

${ }^{2}$ Tendril, Boulder, CO, USA

${ }^{3}$ First Republic Bank, San Francisco, CA, USA

${ }^{4}$ Godaddy, Inc., Sunnyvale, CA, USA

Corresponding Author: Michael Waite

Email address: mbw2113@columbia.edu

Phone Number: +1 212-854-7993

Postal Address:

Mechanical Engineering Department

Columbia University

220 S. W. Mudd Building

500 West 120th Street

New York, NY 10027 USA 


\begin{abstract}
As the tropics and subtropics become increasingly urban, industrial and affluent, energy demands for thermal comfort may evolve differently than it has historically across the global North. Already, heating, ventilation and air conditioning account for 35\% of total primary energy in the United States, and are expected to reach similar proportions in China within 5 years. With increasing population in high temperature areas, electricity demand for increased air-conditioning usage may drive extreme electricity peak demands and total usage. This paper presents comparative estimates of peak and annual electric cooling and heating electricity usage at the city-scale, including both OECD and non-OECD member cities. Our results indicate that mature urban economies of the OECD exhibit a cooling electricity response of 35-90 Watts per ${ }^{\circ} \mathrm{C}$ per capita above room temperature for cooling (interquartile range of estimates). Tropical/subtropical cities outside the OECD (mostly in South Asia, Africa and the Middle East) currently demand just $2-9 \mathrm{~W} /{ }^{\circ} \mathrm{C} /$ capita, indicating significant growth in temperature-dependent electricity demand as air conditioning is adopted. A similar story is unfolding on the heating side, with subtropical cities adopting electric resistive heaters, potentially precipitating additional electricity generation and delivery concerns, particularly electric resistance heating is adopted instead of heat pumps.
\end{abstract}

\title{
Abbreviations
}

- AC: Air Conditioning

- $\quad \mathrm{CDH}$ : Cooling Degree Hours

- $\quad$ CI: Confidence Interval

- $\quad$ EIA: Energy Information Agency

- $\quad$ FERC: Federal Energy Regulatory Commission

- HDH: Heating Degree Hours

- $\quad$ HVAC: Heating, Ventilation and Air Conditioning

- IQR: Interquartile Range

- LDC: Load Duration Curves

- NCDC: National Climatic Data Center

- NOAA: National Oceanic and Atmospheric Administration

- T: Temperature

- $\quad$ TLC: Temperature-Load Curve

- $\quad \mathrm{T}_{\mathrm{t}}$ : Threshold Temperature

\section{Introduction}

Urbanization, rising incomes, and the income elasticity of energy services in emerging economies will largely determine the trajectory of global energy needs (and associated environmental impacts) over the coming decades [1]. As economic development in emerging markets trends towards eventual parity with Organization for Economic Cooperation and Development (OECD) nations, we should likewise expect increasing provision of energy-utilizing services and technologies [2], including: thermal comfort 
(cooling, dehumidification and heating); food storage and preparation (refrigeration, cooking, microwaving); cleaning (washing, drying); work productivity, communication and entertainment (mobile phones, computers and television); and lighting. As population growth, improved living conditions and economic expansion lead to an increasing number of households and businesses, energy requirements will further increase [3, 4].

In developed cities, building energy use accounts for roughly half of all greenhouse gas (GHG) emissions, according to a review of eight U.S. cities [5]. According to a review of ten international cities [6], roughly half of building energy-related GHG emissions is due to electricity generation to serve those areas. Further, the average U.S. GHG emissions for non-baseload electricity generation are $36 \%$ higher than those for baseload electricity generation, indicating higher GHG emissions for temperature-dependent loads [7]. In developing cities, buildings account for a slightly smaller share of city-wide GHG emissions, estimated at $43 \%$ for a case study of Delhi, India [8], using the same system boundaries and methodology as in [5].

Many of the world's largest and fastest-growing cities are located in South Asia and SubSaharan Africa with tropical to sub-tropical climates unlike those of most OECD member cities. Given their climates, tropical regions are expected to see increasing levels of primary energy usage for thermal comfort, as air-conditioning (and even space heating) adoption and conditioned space requirements increase. While appliances, lighting, electronics and computing reduce heating requirements in cold climates, they have an adverse effect on cooling requirements. At the city-scale, HVAC may play an even larger role since building energy use tends to dominate in urban areas and urban areas generally do not have significant opportunities for generation within the city. This may be exacerbated due to heat-island effect, and tendency towards service-economy, which increases the relative share of air-conditioned commercial real estate.

Pachauri and Spreng [9] found that as incomes rise, urban households in India consume more energy per capita and transition from emissions-intensive biomass and kerosene to clean burning LPG and electricity; both trends point towards higher electricity usage.

The thermal comfort-seeking behavior, specifically, has exhibited itself in Delhi's electricity demand being a U-shaped function of ambient temperature with the demand's sensitivity to higher temperatures increasing over time [10]. A similar analysis of 28 Indian states showed the summer electricity demand to be more sensitive to temperature in hotter Indian states and, conversely, the winter electricity demand to be more sensitive to temperature in colder Indian states [11]. Similarly, an extensive study of Mexico's residential electricity usage showed that with increasing income, air conditioning usage increases dramatically in warmer regions [12]. This trend is much more modest in cooler regions where air-conditioning adoption is just beginning to show in higher income areas.

The higher penetration of cooling equipment in warmer climates and heating equipment in colder climates is both intuitive and consistent with historical air conditioning adoption patterns in the U.S.; however, even at a relatively low 500 cooling degree days, penetration exceeds $60 \%$ of U.S. residences [13]. 
To illustrate the potential for vast differences in expected energy needs for thermal comfort between cities in the global north and cities in the tropics/subtropics, consider Delhi, India. With its large population, hot summer and hot-humid monsoon season, Delhi's has no analog in the global north, but is typical of South Asia. With temperatures approaching 50 ${ }^{\circ} \mathrm{C}\left(122^{\circ} \mathrm{F}\right)$ during intense heat waves, peak electricity demands for cooling in Delhi may exceed $150 \%$ of the peak electricity demands for cooling in New York City. In addition to higher temperatures, the cooling season is also much longer. As such, over the past three years, Delhi had four times as many cooling-degree days as New York City (assuming a $65^{\circ} \mathrm{F}$ basis). Compounded by (a) "leaky" building envelopes in developing world cities (sometimes intentionally designed to accommodate natural ventilation), (b) heat-island effects, and (c) increasing urbanization, will impact peak electricity demand in emerging megacities. The interrelated effects among these factors are complex; however, the recent availability of higher resolution electricity data provides an opportunity to evaluate current energy usage of specific cities within a wide and varied sample of urban areas.

In this paper we analyze hourly electricity demand profiles for 17 electric utilities serving emerging market cities in South Asia, the Middle East and Africa (non-OECD), and provide comparison to 18 mature urban economies in the U.S. and Japan (OECD). The intent is to identify the relationship between electricity demand and ambient temperature in order to determine the cooling and heating electricity response to temperature; in turn, the contribution of cooling and heating to overall electricity usage is estimated in each urban area. We focus on thermal comfort as compared to other end-use energy services because it is the largest driver of peak electricity demand in the residential and commercial sectors [14-16], which in turn dominate the energy footprint of population-dense cities [6]. Peak demand dictates capacity requirements for generation, transmission and distribution infrastructure. The difference between peak demand and baseload demand -- driven in large part by thermal comfort requirements -- has significant implications for choice of generators, GHG emissions, integration of renewables and load factors, which in turn drive utility economics.

We limit our inquiry to final (or "site") electricity. Nearly all cooling is provided by electricity whereas heating is provided by several possible sources, primarily fossil fuels and likely varying significantly across our study set of cities. Therefore, this study offers more quantifiable insight into cooling than heating; however, it is likely that increased heating for thermal comfort in tropical and sub-tropical regions may come primarily from electric heating. Hence, even though we focus on cooling, we do include electricity for heating in our analysis and discussion.

\section{Background to Analytical Approach}

The methods for analyzing, estimating and predicting building energy usage are plentiful and have been reviewed in detail elsewhere [17-20]. Such an in-depth review is beyond the scope of this paper; however, this section reviews various methods considered for the present study to provide readers with the authors' rationale and basis for the analytical approach used. 


\subsection{Integrated Assessment Models}

Eom et al [21] identify five structural variables that drive long-term building energy use: (1) population growth, (2) economic growth, (3) urbanization, (4) per-capita floor space, and (5) demand for building energy services. This formulation is supported by [6] and [22], and serves as the foundation for a widely used building energy sub-routine of the Global Change Assessment Model (GCAM) [23].

GCAM belongs to a class of models known as integrated assessment models, which approximate a web of interactions between endogenous variables given exogenous boundary conditions [23]. Integrated assessment models such as GCAM are well-suited to high-level, economy-wide scenario analysis (see [24] and [25] for two particularly relevant examples).

\subsection{Physical Models}

On the other end of the spectrum are physical models that require detailed climatological, meteorological, and building systems design, construction and inventory data. Physical models are well-suited to answer specific inquiries regarding near-term energy use at high resolution. They do not attempt to model interactions with the broader economy. There are many such models in the literature and in common practice, covering a wide range of building typologies and climate zones, and therefore, we only attempt a cursory catalog of salient examples.

Building energy demand for thermal comfort (in particular) has been evaluated for many regions of the world: China [26, 21]; Hong Kong [27]; Malaysia [28]; Jordan [29]; Turkey [30]; Europe [31] and multiple regions [32]. There have also been a large number of studies looking at the effect of climate change on heating/cooling demand in buildings: Australia [33]; Burkina Faso [34]; Switzerland [35]; Honk Kong [36]; UAE [37]; Tehran [38]; Germany [39]; Multiple regions [26]; Subtropics [40]; a global outlook [41] and two review articles $[42,43]$.

Physical models are the most widespread tool for simulating energy demand in a specific building, particularly for their ability to evaluate the effects of potential technical modifications to those buildings or design options for new buildings. However, our study takes an urban metabolism approach in which the behavior of the entire city is of interest. Few cities in the world publish full building-stock inventories (including residential, commercial, industrial, government and public buildings such as hospitals, libraries and schools) sufficient to reasonably estimate total urban energy demand from the bottom-up. Even if this information were available widely, the performance of individual buildings is highly variable and the "smoothing" effect that occurs in aggregating buildings across a city would render this effort far too complex for the goals of the present study. For this reason, we opt for a statistical approach using high time resolution electric utility data.

\subsection{Statistical Models}

Statistical energy demand models include regression, pure time-series, and mixed-method econometric models. Rallapalli and Ghosh [44] apply a non-stationary time-series model to 
accurately predict electricity demand in all 5 regional power grids of India. Their model outperforms official forecasts of the Central Electricity Authority of India for both insample and out-of-sample prediction. Econometric approaches to estimate income elasticity of electricity usage have also been developed for Korea [45], Switzerland [46], United Kingdom [47] and India [48-50]; these approaches can be cataloged into macro- and micro-level approaches. Macroeconomic approaches employ top-down, national/subnational summary statistics $[1,51]$, whereas microeconomic approaches use bottom-up household survey data to analyze differences across heterogeneous sub-groups [48-50].

\subsubsection{Regression Models}

Diurnal and seasonal variability in urban electricity demand is driven, in large part, by human response to meteorological factors [14,52]. A previous study of the relationship between summer peak electricity demand in Israel and a host of meteorological parameters demonstrated that a simple linear model with just a few predictors, namely temperature and humidity, performs as well as more complex models with many additional predictors. In a similar study of Australia, a complex demand forecast model with over 50 model parameters was ultimately reduced to include only daily maximum and minimum temperatures and relative humidity to estimate electricity demand [52].

A study of five Chinese cities in distinct climate zones estimated baseline and future cooling and heating demand for a single generic air-conditioned office building [25]. While orthogonal variables (dry bulb temperature, wet bulb temperature and solar radiation) were identified through principal component analysis, the resulting model was essentially a proof of concept and particular to a simulation of a specific building's energy usage.

\subsubsection{Change-Point Regression Models}

The primary goal of this paper is to develop a standard method to assess temperaturedependence of urban electricity demand without the need for detailed city-wide building inventories. For this task, we propose change-point regression models, widely used in building energy audits and energy management references to compare buildings to one another, to a reference case, or to itself pre- and post-modification [53-55]. Fig. 1 shows the general form of a five-parameter, steady-state, univariate model for electricity use as a function of ambient temperature.

In Fig. $1, E_{0}$ represents the temperature-independent electricity usage; $s_{1}$ is the slope of the heating signal in the electricity data; $s_{2}$ is the slope of the cooling signal in the electricity data; $T_{1}$ is the temperature below which the heating signal is detected; and $T_{2}$ is the temperature above which the cooling signal is detected. The model therefore has the general form:

$$
\mathrm{E}=\mathrm{E}_{0}+\mathrm{s}_{1}\left(\mathrm{~T}_{1}-\mathrm{T}\right)^{+}+\mathrm{s}_{2}\left(\mathrm{~T}-\mathrm{T}_{2}\right)^{+}
$$

Change-point regression allows complex dynamics to be reduced to a multiple parameter model that can be evaluated using minor adjustments to traditional linear regression analysis when the system being evaluated responds to a variable in two or more regimes 
[56]. In its most basic form, this is used when the influence of a single variable (ambient temperature, $T$, in the case of Eq. 1 ) on some response (energy use, $E$, in the case of Eq. 1) depends on whether it is less than or greater than some "change-point" value. For this study, in climates with both cooling and heating electricity responses: At low ambient air temperatures, electricity demand decreases as temperature increases because electric heating demands are reduced; however, at higher ambient air temperatures, electricity demand increases as temperature increases.

Statistical methods are used to determine both the change-point value(s) of the variable $\left(T_{1}\right.$ and $T_{2}$ in Fig. 1 and Eq. 1$)$ and the linear response of the system $\left(s_{1}\right.$ and $s_{2}$ in Fig. 1 and Eq. 1) to the variable in the regimes on either side of that change-point [56]. The history of the application of change-point regression, particularly in biostatistics, has been welldocumented [58]. These methods were later adapted to estimate individual building cooling demands [59] and changes in building energy demands due to building retrofits [60]. Change-point regression models are now used as a standard data-driven modeling method in energy auditing, management and estimating [61].

This approach has been used at the aggregate building scale in a few previous studies. Bessec and Fouquau [62] evaluate the temperature dependence of electricity demand at the national scale for countries in Europe. Moral-Carcedo and Vicens-Otero [63] provide a detailed assessment for Spain. We extend this methodology to city-scale electricity demand for a large number of cities, spanning multiple climates and economic zones. The purpose of our model is not precise prediction (we leave that to the electric utilities themselves), but rather a generalized framework that can be applied across multiple, data-sparse cities simultaneously with reasonable accuracy.

\section{Analytical Approach}

Energy demand projections abound, but are often saddled with excessive complexity [64]. Complexity translates to proliferation of estimated model parameters, which in turn compounds uncertainty, limits degrees of freedom, diminishes generalizability and obfuscates interpretability.

A review of multi-decadal energy demand forecasts for the U.S. economy was found to be consistently off the mark [65]. Forecasts by the U.S. Department of Energy for 1975 to 2000 overestimated demand by up to a factor of 2 . In fact, of a dozen independent energy forecasts evaluated, only one proved accurate [66]. "A perception that a complex model with extensive input data produces more accurate results might not be always true" ([64], pg. 8). The importance of parsimony in energy modeling cannot be overstated [67].

To side-step many of these pitfalls, we propose a well-defined, theory-driven and empirically-supported iterative change-point regression model for estimating urban electricity demand for cooling and heating. Broadly speaking, population and economy size and functions drive baseload electricity demand at annual to decadal timescales; climate drives seasonal variability; and human behavior, physiology and meteorology drive diurnal patterns. This study considers the latter three -- climate, weather and human physiology -- 
in the context of demand for electricity for thermal comfort. The objective of this study is to answer four key research questions:

1. What is the current level of electricity demand for cooling and heating services in major emerging cities, as measured by the cooling and heating electricity response in units of $\mathrm{MW} /{ }^{\circ} \mathrm{C} /$ capita referenced to a computed threshold temperature?

2. What is the magnitude of seasonal electricity usage for cooling and heating in major emerging cities, as measured by total GWh?

3. What portion of the peak electricity demand corresponds to electricity demand for thermal comfort?

4. How does the share of annual electricity usage used for cooling and heating compare across cities, as measured by a fraction of the total?

\subsection{Data}

At present, there is scant baseline information publically-available on urban electricity demand for a cross-section of global cities. This article aims to fill that gap. In addition to the tables, figures and analysis reported here, all of the underlying data is curated and made freely available (with citation) on Github. We encourage fellow researchers to fork the repository and contribute new data via pull request.

This study combines hourly time resolution electricity demand and meteorological data with annual census information for 35 global cities.

The starting point for identifying major emerging cities was the UN World Urbanization Prospects [68], subset to the 100 fastest growing cities with more than 2 million inhabitants. For comparison, data for US cities was collected from the Federal Energy Regulatory Commission and the US Energy Information Administration. Appendix Table A1 summarizes the data sources used.

\subsubsection{Weather Data}

High-resolution weather data are indispensable to accurate energy demand forecasts $[14,15,52,69]$. Fortunately, national weather services and climate information centers such as the U.S. National Oceanic and Atmospheric Administration (NOAA), Britain's Met Office, and India's Institute for Tropical Meteorology (IITM), collect, curate, analyze and publish meteorological data from thousands of weather stations worldwide. The appropriate resource was used for each city analyzed; Appendix Fig. A1 compares some climate characteristics for the cities considered in this study.

\subsubsection{Demand Data}

Hourly electricity demand data was collected for 18 OECD and 17 non-OECD electricity utilities, system operators and regulatory bodies serving cities of interest for the most recent years for which data is available. Data was collected on as consistent a basis as possible given the recording practices of the individual entities; however, a few exceptions should be noted: 
1. The National Capital Territory of Delhi (population 23 million) was disaggregated into five "cities", each served by a distinct and non-overlapping electricity distribution company; see the Appendix "Supplementary Information" for details.

2. Data for Beirut, Lebanon and Amman, Jordan were estimated from national data. The Jordanian utility NEPCO provided monthly ratios of electricity usage for Amman compared to Jordan as a whole. The ratio was approximately $50 \%$ for all the months. (Note: Amman is the only major city in Jordan.) The Lebanese utility EDL provided ratios of $15 \%$ from $8 \mathrm{am}$ to $12 \mathrm{am}$, and $22 \%$ from $12 \mathrm{am}$ to $8 \mathrm{am}$ for Beirut as compared to Lebanon as a whole.

3. Data for Abidjan, Ivory Coast and Dakar, Senegal were estimated from country level loads by the utilities themselves: monthly ratios of peak demand at city-level feeders compared to peak demand for the national grid as a whole were applied.

4. Data for Philadelphia includes the surrounding areas.

5. Data for Manila includes the whole Luzon islands.

While variability in the data definitions and integrity is inevitable in a study covering such broad areas in both developed and developing countries, we are confident that our review and processing of the data is sufficient to serve the purposes of our analysis. Where we think source data may have affected the results for particular locations, we have included explanations and caveats in the interpretation of our results.

\subsubsection{Population Data}

Population data was collected from many sources as per Appendix Table A1. They are used to normalize cooling and heating electricity response and usage estimates to a per capita level as described below.

The population data collected for some U.S. cities from EIA were in the form of "residential customer count". They were therefore multiplied by the U.S. average number of persons per household (estimated to be 2.63 by the U.S. Census Bureau) to obtain a population service count. For these cities, the collected load data from FERC were related to the corresponding EIA customer count by merging the FERC 714 form with the EIA 826 form.

\subsection{Methodology}

Two main analyses are performed on the set of city-year data, described above: (1) Estimating the sensitivity of the daily peak demand of electricity to ambient temperature, and (2) estimating the annual amount of electricity used for thermal-comfort seeking (cooling and heating). The below sections detail the key concepts and methodology used to obtain these estimations.

\subsubsection{Cooling and Heating Degree Hours}

For every city-year combination, Cooling Degree Hours is defined as the sum at every hour of the difference between the recorded temperature and some reference temperature, $\mathrm{T}_{\text {ref. }}$. We have defined this as the threshold temperature. If this difference is negative, it is taken as 0 : 


$$
\mathrm{CDH}=\sum_{\text {hour }=1}^{8760}\left(\mathrm{~T}_{\text {observed,hour }}-\mathrm{T}_{\mathrm{ref}}\right)^{+}
$$

In a similar way, Heating Degree Hours is defined as the sum at every hour of the difference between the threshold temperature and the observed temperature at that hour. If this difference is negative, it is taken as 0 :

$$
\mathrm{HDH}=\sum_{\text {hour }=1}^{8760}\left(\mathrm{~T}_{\text {ref }}-\mathrm{T}_{\text {observed,hour }}\right)^{+}
$$

In other words, $\mathrm{CDH}$ and $\mathrm{HDH}$ represent the number of degrees per year that require cooling and heating, respectively, to reach the degree of thermal-comfort set by the "comfortable" threshold temperature. It is important to note that this is not necessarily the air temperature at which people are comfortable, but the "balance point" temperature at which other loads (e.g. internal equipment heat gains and solar gains) balance heat loss or gain with HVAC services. This temperature is usually set at $18{ }^{\circ} \mathrm{C}$ or $20^{\circ} \mathrm{C}$ in heating/cooling degree reporting, however the subsequent sections will derive a threshold temperature that is specific for the city-year considered using change-point regression.

\subsubsection{Temperature-Load Curve (TLC) \& Threshold Temperature (Tt)}

In performing our analysis, we noted a near-V-shaped behavior (i.e. a single change-point and, thus, no difference between $T_{1}$ and $T_{2}$ shown in Fig. 2 and Eq. 1 ) in the cities' data. Therefore, we define this single change-point temperature as the Threshold Temperature $\left(T_{t}\right)$ and set $T_{1}=T_{2}=T_{t}$. With this assumption, we applied the change-point regression approach to the pairwise observations of hourly temperature and electricity demand in megawatts (MW) in order to develop a "temperature-load profile" of every city-year-hour combination. Each year is evaluated separately to identify any changes to the electricity demand's response to temperature over time. Each hour of the day (1-24) is evaluated separately to control for diurnal rhythms and thermal mass effects that become observable through hysteresis behavior. Separate city-year-hour models also allow for checking the stability of results across multiple models.

Iterative testing has shown that to obtain a profile suitable for a regression fit, temperature-load data must be available for at least the equivalent of 3 months to capture a sufficiently wide range of temperatures. Therefore, all the collected data were filtered and a small number of city-year combinations were omitted as a consequence.

Economic activity is typically lower on weekends compared to weekdays, and electricity demand is commensurately lower. To account for this effect, which is unrelated to temperature, weekends were analyzed separately from weekdays.

Plotting the electricity demand against temperature gives the Temperature-Load Curve (TLC). Depending on the prevalence of cooling and heating appliances and share of individual building types, as well as many other factors in each city, the form of the 
temperature-load profile varies. Cities with distinct cooling and heating seasons (such as New York City, latitude $=40.65^{\circ}$ ) will have a V shaped TLC. The right side of the curve represents the cooling regime: As temperature increases, demand for electricity increases because of cooling requirements. The cooling regime, and therefore the city's sensitivity to high temperatures is characterized by a positive coefficient referred to in this paper as the Cooling Coefficient ( $s_{2}$ in Eq. 1). The left side of the curve represents the heating regime: As temperature decreases, demand for electricity increases because of heating requirements.

The cities' sensitivity to cold temperatures is characterized by a coefficient ( $s_{1}$ in Eq. 1 ) referred to in this paper as the Heating Coefficient, which tends to be lower in absolute terms than the Cooling Coefficient because it does not capture all heating sources and efficiency effects. In many cities, heating needs are met predominately by natural gas or heating oil, and not electricity, although some electrical heating exists, and even with other fuel sources electricity needed to operate pumps and fans that distribute hot water and air. Because our study focuses on electricity only, and no other fuels, our estimates of integral energy usage for electric heating will almost certainly be underestimates of total heating energy in a city.

The threshold temperature, $T_{t}$, is the observed temperature above which the cooling signal in the electricity data begins to dominate the heating signal; it does not necessarily mean there is no cooling below this temperature or no heating above this temperature.

In contrast to New York City (described above), most cities in the tropics and sub-tropics tend to have cooling but no discernable heating signal. For example, Dakar Senegal (latitude $=14.7^{\circ}$ ) has a distinct cooling season only, as can be seen from the TLC (Fig. 2).

A third category is cities located in temperate climates with little-to-no cooling and heating infrastructure and, thus, no strong relationship between temperature and electricity demand. The TLC for these cities will lack a definite threshold temperature and the slope of the regression will not be significantly different than zero.

\subsubsection{Cooling and Heating Electricity Responses}

To quantify the TLC for a set of global cities, cities are divided into two groups: (1) Cooling and Heating cities, and (2) Cooling or Heating cities. For cities with cooling only or heating only, a simple linear regression is used in place of the change-point regression analysis to model demand as a function of temperature. For cities with cooling and heating, a changepoint regression is performed where two restricted linear models (one for cooling, one for heating) and the change point defining the boundary between the two regimes are iteratively estimated to minimize the total sum of square root errors. A bootstrap restarting method is applied to escape local optima when spurious local optima or multiple optima exist. The intercept and beta coefficients $\left(s_{1}, s_{2}\right)$ for the two linear models are estimated simultaneously by ordinary least squares given an initial condition of the "breakpoint" between the two linear regressions. Since a large number of city-year combinations are considered in this study, we developed functions to automate the process in $\mathrm{R}$ [70]. For every city-year combination, the first step of the algorithm is to compute the interquartile range (IQR; the range between the 25 th percentile and the 75 th percentile) of the temperature distribution. 
The Heating Coefficient, $s_{1}$, Cooling Coefficient, $s_{2}$, the threshold temperature, $T_{t}$, along with the statistical significance of all parameter, are extracted and saved for every city-year scenario at daily peak load observations. This process is then repeated for every hour of the day (0-23) for each city-year combination. That is, a linear/change-point regression model is fit to all the weekday/weekend midnight, 1ams, 2ams, etc. resulting in 48 TLCs for each city-year combination. This will be used in the next section to estimate integral electricity usage for cooling and heating.

To illustrate this, we show the TLC (Fig. 3) for New York City in 2012 at midnight, 6am, $12 \mathrm{pm}$ and $6 \mathrm{pm}$. Note the change in slope in cooling and heating electricity response depending on time of day.

The Cooling and Heating Coefficients obtained at every hour for every city-year scenario are a measure of demand for electricity for thermal comfort; that is, how much electricity is required to keep residents in a city comfortable as ambient air temperatures change. Coefficients are expressed as positive values in $\mathrm{MW} /{ }^{\circ} \mathrm{C}$ and therefore represent the incremental change in electricity demand for every $1^{\circ} \mathrm{C}$ change as the air temperature moves away from the threshold temperature in either direction.

\subsubsection{Integral Electricity Usage for Cooling and Heating}

After estimating the characteristic electricity demand for cooling and heating at each hour of the day (0-23) for each year from the TLC, the estimated total annual electricity usage for thermal comfort is computed by multiplying electricity demand per ${ }^{\circ} \mathrm{C}$ by the degree hours computed by Eqs. 2 and 3. Before computing integral electricity usage, a data filter was applied to select city-year combinations containing the equivalent of at least 350 days of hourly observations. 350 days was chosen instead of 365 days to allow a modest tolerance for missing data.

$$
\text { CoolingEnergy }_{\text {city,yr }}=\sum_{\text {hour=1 }}^{8760} \text { C oolingDemand }{ }_{\text {city,yr,hr }} \times\left(\mathrm{T}_{\text {observed,city,yr,hr }}-\mathrm{T}_{\mathrm{t}, \mathrm{city}, \mathrm{yr}, \mathrm{hr}}\right)^{+}
$$

HeatingEnergy $_{\text {city,yr }}=\sum_{\text {hour }=1}^{8760}$ HeatingDemand $d_{\text {city,yr,hr }} \times\left(\mathrm{T}_{\mathrm{t}, \mathrm{city}, \mathrm{yr}, \mathrm{hr}}-\mathrm{T}_{\text {observed,city,yr,hr}}\right)^{+}$

For any city-year-hour combination, if the Cooling Coefficient or Heating Coefficient determined per Section 3.2.3 is not significant at the $90 \%$ confidence interval, it is set to zero and not included in the annual electricity usage calculations per Eqs. 4 and 5.

\section{Results and Discussion}

The following section presents results and discussion for each of four stated research objectives. The results of the analysis described above and presented here represent the 
first comparative analysis of electrical cooling and heating demand at the city-scale, including both OECD and non-OECD member cities.

\subsection{Cooling}

A significant cooling signal was detected (90\% confidence level) for 33 of 35 cities analyzed. The only cities without a clear cooling signal in all years analyzed were Mbabane, Swaziland (elev. $1243 \mathrm{~m}$, lat. $-26^{\circ}$, long. $31.3^{\circ}$ ) and Nairobi, Kenya (elev. $1661 \mathrm{~m}$, lat $-1.3^{\circ}$, long. $36.8^{\circ}$ ). Both cities are at high elevation, with mild climates and cool nights, suggesting that electrical cooling is unnecessary much of the year, and thus adoption of capitalintensive AC is commensurately low, even by the non-OECD cities' standard. By comparison, Abidjan, Cote d'Ivoire had no detectable cooling signal as recently as 2010, but now has a highly significant $(99 \% \mathrm{CI})$, though moderate in scale, cooling electricity response of approximately $3 \mathrm{~W} /{ }^{\circ} \mathrm{C} / \mathrm{capita}^{1}$, suggesting very recent uptake of cooling appliances.

In Accra, Ghana, both the effect of temperature on electricity demand, and the significance of that effect are increasing year-on-year. Virtually across the board ${ }^{2}$ among non-OECD cities, this holds true: the cooling electricity response is higher now (most recent year data is available) than even just a few years ago (first year data is available). The trend holds true (increasing, but not strictly monotonic) for Abidjan, Cote d'Ivoire; Accra, Ghana; Amman, Jordan; Chandigarh, India; Dakar, Senegal; and Manila, Philippines. (See Appendix Table A2 for relevant quantities.) Fig. 4 illustrates these phenomena for Abidjan, Dakar and Manila. It shows daily peak demand increasing year-on-year, and its relationship to temperature intensifying.

Fig. 4 suggests significant, latent, unmet demand for indoor thermal comfort services in emerging market cities. As incomes continue to rise, so will penetration of vaporcompression refrigeration window-units (e.g. AC) and resistive electrical heaters in the near term, and central heating/cooling and electric heat pumps in the long-term. Electricity demand for cooling, dehumidification and heating will rise accordingly. How high it will ultimately go, is a central question of this research. As an upper-estimate, we can presuppose that demand for thermal comfort services will reach eventual parity with OECD

1 The units of "W/ $/{ }^{\circ} \mathrm{C} /$ capita" are used for cooling and heating electricity response throughout the presentation and discussion of the results. It represents the average incremental electric power in one hour required for thermal comfort for a $1^{\circ} \mathrm{C}$ change in ambient air temperature per person.

${ }^{2}$ The only non-OECD cities with a measurable cooling signal and more than one year of data but no observed increase in cooling electricity response over the reporting period were Delhi and its subdistricts, and Beirut, where the changes were minimal. In Delhi, it is widely known that overall demand for cooling is increasing (Cohen 2014 Dissertation), and thus the apparent decrease from 2011 to 2012 may simply be due to noise in the data. Annual trends can only be established with at least three years of data. 
cities on a $\mathrm{W} /{ }^{\circ} \mathrm{C} /$ capita basis as technologies, infrastructure and building design and construction practices appropriate for mechanically cooled buildings are adopted.

Integrating cooling and heating electricity response over expected $\mathrm{CDH}$ and $\mathrm{HDH}$, respectively, for a given city yields a lower-bound estimate of total annual electricity usage for indoor thermal comfort. This method can be used for historical, current-year or future projections by adjusting the per-capita heating/cooling electricity response, heating/cooling-degree hours and population. Such adjustments can be used to assess change over time along the development spectrum and incorporating the effects of climate change.

As a group, non-OECD cities were found to have maximum per-capita cooling electricity responses ranging from $0-13 \mathrm{~W} /{ }^{\circ} \mathrm{C} /$ capita in all but two locales ${ }^{3}$. By comparison, cooling electricity responses in the OECD ranged from $15-151 \mathrm{~W} /{ }^{\circ} \mathrm{C} /$ capita. The interquartile range (IQR) of cooling responses in non-OECD cities was $2-9 \mathrm{~W} /{ }^{\circ} \mathrm{C} /$ capita compared to 35 $90 \mathrm{~W} /{ }^{\circ} \mathrm{C} /$ capita in the OECD. The median per-capita cooling electricity response was tentimes higher in OECD compared to non-OECD cities $\left(50\right.$ versus $5 \mathrm{~W} /{ }^{\circ} \mathrm{C} /$ capita, respectively).

The only OECD cities in our study with low per-capita cooling demands approaching those of the non-OECD set, were San Diego and Honolulu (at 21 and $22 \mathrm{~W} /{ }^{\circ} \mathrm{C} /$ capita, respectively). These two locales have pleasant, coastal climates with annual average temperatures at a near-perfect $22^{\circ} \mathrm{C}$.

Within the OECD set, there is substantial variation. Of U.S. cities with distinct cooling and heating seasons, higher-density cities generally required less cooling electricity per capita for a step change in temperature than did low-density cities. Low-density cities were found to have the highest per-capita cooling electricity response, likely attributable to higher percapita residential-commercial air-conditioned space, proximity to inexpensive coalgenerated electricity and general trends related to later urbanizing areas.

US cities that primarily developed post-World War II show particularly strong cooling electricity responses to temperature: Chattanooga, TN $\left(151 \mathrm{~W} /{ }^{\circ} \mathrm{C} /\right.$ capita); North Little Rock, AK (128); Springfield, IL (125); Omaha, NE (113); Indianapolis, IN (99). By comparison, population dense and older New York City had computed cooling electricity response values of less than $40 \mathrm{~W} /{ }^{\circ} \mathrm{C} /$ capita. A group of OECD cities that share some features with both groups, and perhaps unique historical development characteristics, fall in a cooling response range of $66-92 \mathrm{~W} /{ }^{\circ} \mathrm{C} /$ capita. The per-capita peak electricity demand, and the estimated contribution of cooling to this peak demand, is shown in Fig. 5 for all cities analyzed; the fraction of total peak electricity demand required for cooling is shown in Fig. 6. (Appendix Table A3 summarizes relevant quantities included in this discussion and required to create Figs. 5 and 6.)

${ }^{3} \mathrm{Amman}$, Jordan at $47 \mathrm{~W} /{ }^{\circ} \mathrm{C} /$ capita; and New Delhi (not to be confused with Old Delhi nor NCT Delhi as a whole; only the relatively new governmental district) at $40 \mathrm{~W} /{ }^{\circ} \mathrm{C} /$ capita. 
Fig. 5 shows a clear distinction in peak demand between OECD and non-OECD cities, save for the central governmental area of Delhi, which behaves similarly to high density OECD cities. Tacoma, with a far lower estimated cooling demand at the time of peak electricity demand, can be explained by that demand occurring during the heating-dominated season; this indicates deep penetration of electric heating, reflecting Tacoma's easy access to hydroelectric power.

Fig. 6 shows more clearly the trend (and expectation) that more developed cities require more cooling as a portion of their peak demand. The portion of peak electricity demand in non-OECD cities remains relatively small when compared to most OECD cities. As AC adoption grows, it is expected that the peak demand will grow, as well as the difference between the peak demand and the average demand (and base demand). This further suggests that other electric appliances are first adopted before air conditioning.

New Delhi (NDMC; the seat of government), at $40 \mathrm{~W} /{ }^{\circ} \mathrm{C} / \mathrm{capita}$, has a per-capita cooling electricity response roughly four times that of neighboring parts of the city. This reflects stark differences in the building stock: many large government buildings have been retrofitted for air-conditioning, a departure from traditional open-envelope building design. Cooling demand in neighboring districts of Delhi will likely catch up quickly as AC becomes commonplace in middle-income households and businesses in all quarters of the city.

Amman, Jordan, at $47 \mathrm{~W} /{ }^{\circ} \mathrm{C} /$ capita, has per-capita cooling electricity response nine times higher than that of Beirut, although the cities are less than a 150 miles apart and have similar climates (Beirut is more temperate given its location on the Mediterranean). This may be explained, in part, by Amman being the only major city in Jordan (and thus may be home to a disproportionate level of economic activity compared to its population), whereas Lebanon has several cosmopolitan cities. As noted above, Amman and Beirut electricity demands were estimated from national data; potential discrepancies in our analysis are possible due to this assumption.

\subsection{Heating}

Given that heating relies on a mix of on-site sources (electricity typically being less widely used, particularly in developed countries), a peak heating electricity presentation analogous to that shown for cooling in Section 4.1 is not relevant; however, heating electricity was included in the annual thermal comfort electricity usage calculations described in Section 4.4, below. That said, some comments pertaining to the electricity demands for heating are pertinent. (Appendix Table A4 summarizes relevant quantities related to the heating analysis.)

A significant heating signal in the electricity data was detected ( $90 \%$ confidence level) for 21 of 35 cities analyzed: As temperatures decrease below the threshold temperature unique to each city, electric demand increases. That is, an inverse-linear relationship is observed between temperature and electricity demand below the threshold temperature, typically $15-25^{\circ} \mathrm{C}$ in this study, depending on the city. The threshold temperature tends to be lower in OECD cities than in non-OECD cities, indicating that higher internal heat gains from electrical and other equipment, along with wider usage of air-conditioning 
equipment, causes the shift from heating- to cooling-dominated electricity used for thermal comfort at lower ambient temperatures in more developed cities.

Cities with no significant heating signal fall into two categories: (1) tropical, coastal or otherwise mild climates with little need for heating, and (2) cities that likely will require heating for indoor thermal comfort during parts of the year, but have yet to reach significant penetration rates of heating appliance ownership (or do not have the types of large, complex buildings that use central system to heat water or air for distribution, thus requiring pumps and fans). Category two are of particular interest because they will undoubtedly change significantly over the next several years and decades as incomes rise, the cost of heating appliances come down, and western living standards are sought. The potential for wider adoption of electric heat pumps will be an influential development to monitor, as it may not be possible to consider peak demand a summer issue alone.

Non-OECD cities that do currently have statistically significant heating electricity signals include Amman at $30.5 \mathrm{~W} /{ }^{\circ} \mathrm{C} /$ capita, Beirut $\left(1.2 \mathrm{~W} /{ }^{\circ} \mathrm{C} /\right.$ capita), Chandigarh $(4$ $\mathrm{W} /{ }^{\circ} \mathrm{C} /$ capita), Delhi W-SW-S districts $\left(2 \mathrm{~W} /{ }^{\circ} \mathrm{C} /\right.$ capita), Delhi Military Contonement $(7$ $\mathrm{W} /{ }^{\circ} \mathrm{C} /$ capita $)$, Delhi NW-N districts $\left(1.5 \mathrm{~W} /{ }^{\circ} \mathrm{C} /\right.$ capita), Mbabane $\left(3.6 \mathrm{~W} /{ }^{\circ} \mathrm{C} / \mathrm{capita}\right)$ and Nairobi $\left(1.22 \mathrm{~W} /{ }^{\circ} \mathrm{C} /\right.$ capita). In Chandigarh and Nairobi, per-capita heating electricity response were not significantly different from zero as recently as 2011, but have since become significant and increased year-on-year in each of the past three years. We expect this trend to continue (increasing demand, but not strictly monotonic) for years to come as more households and businesses adopt space heating.

The case of Amman may be particularly illustrative of heating system transitions. Jordan is higher on the development spectrum than India and sub-Saharan Africa; it experiences cold winters, though they are more mild than those of the U.S. and Europe. Amman's fairly high heating signal indicates some adoption of electric heating, perhaps with the combined effects of high efficiency heat pumps remaining too expensive and moderate annual heating degree hours causing much of this adoption to be in the form of electric resistance heating.

\subsection{Peak Load Analysis Summary}

Table 1 summarizes the key parameters in assessing the effects of thermal comfort on peak electricity demands in the study urban areas, which are discussed in more detail in Sections 4.1 and 4.2, above. Of all non-OECD cities with at least three years of data (to establish trend) and a measurable cooling signal, five of six saw their cooling electricity response increase over the period of record. This suggests continued, increasing penetration of airconditioning and increasing square-footage of air-conditioned space.

OECD cities exhibit both significantly higher peak demand per capita and higher estimated peak cooling demand per capita, compared to cities in non-OECD countries (Amman remains an outlier). Examining Delhi-NDMC in this context indicates the potential future expectation for other non-OECD cities and they continue to develop. Greater penetration of $\mathrm{AC}$ equipment will push the non-OECD countries to higher peak electricity demands with potentially serious implications for the development of those electricity systems. 
How AC is adopted and used in the developing, non-OECD cities, and the associated fluctuations in daily and seasonal demand will affect the type of electricity generators that can meet the cities' demands, as well as the economics of the overall electricity system due to the effects of temperature-dependent electricity demands on the capacity factor of generators required to meet the most extreme conditions.

As an example, the potential for extreme high temperatures in Delhi could result in cooling electricity demands far exceeding those of OECD cities. If Delhi's threshold temperature and cooling electricity response were to become similar to those estimated for the dense developed cities of New York City or Tokyo, the peak cooling electricity demand would equal $1262 \mathrm{~W} /$ capita or $1446 \mathrm{~W} /$ capita, respectively. If Delhi's threshold temperature and cooling electricity response were to become similar to the less dense developed cities of North Little Rock or Chattanooga, the peak cooling electricity demand would equal 3244 $\mathrm{W} /$ capita or $4357 \mathrm{~W} /$ capita. As a point of comparison, in the analysis described in this paper, Chattanooga had the highest per capita peak cooling demand, $1685 \mathrm{~W} /$ capita. As such, depending on how Delhi develops and adopts air conditioning, challenges of a scale significantly greater than those seen in the OECD are possible.

The contribution of heating to electricity demands is also clear in both OECD and non-OECD cities (particularly those with low temperatures during some portion of the year). As electric heating, particularly through the use of electric heat pumps, becomes more widely adopted, their influence on electricity demands will grow and, in some climates, may surpass the influence of cooling on electricity demands.

\subsection{Annual Electricity Usage Analysis Summary}

In addition to the implications of the peak demand, the total electric energy required for thermal comfort services is also of interest. Fig. 7 indicates that estimated per capita electricity usage for thermal comfort varies remarkably across cities, ranging from 0-3132 $\mathrm{kWh} /$ capita/year for cooling, 0-2195 kWh/capita/year for heating and 0.25-4808 for total thermal comfort.

Midsize U.S. cities with low population density -- representative of the post-World War II suburban boom -- including Chattanooga, TN; Indianapolis, IN; Little Rock, AK; Springfield, IL; and Omaha, NE; were found to have the highest estimated per-capita electricity usage for thermal comfort services. This is likely attributable to large, single family homes, bigbox stores and more air-conditioned real-estate in general (per-capita) compared to cities with a more compact and vertical urban form. High-density OECD cities, such as New York and Tokyo, use less than half as much electricity per-capita for cooling and heating as their more sprawling counterparts. Building envelope performance (e.g. insulation levels and airtightness) may also be a factor. We may speculate that moderate climates without extreme heat or cold or with very low energy costs may not have had a historical incentive to improve building envelope performance; however, these effects would require extensive study of representative buildings across the cities and, likely, detailed physical modeling. (Appendix Tables A2 and A4 summarize relevant quantities used to create Fig. 7.)

Subtropical cities, in general, were found to have very low integral electricity usage for cooling, despite a large number of cooling degree hours. For example, Delhi, Singapore, 
Antigua, Dakar, Accra, Abidjan and Manila, have cooling requirements ranging from 53-370 kWh/capita/year, compared to 2193-3782 kWh/capita/year for Midwestern U.S. cities. This is despite the fact that the former have far higher $\mathrm{CDH}\left(50,000-70,000{ }^{\circ} \mathrm{C} \cdot\right.$ hour $)$ than the latter $\left(12,000-27,000{ }^{\circ} \mathrm{C} \cdot\right.$ hour $)$. This indicates that cooling is only just emerging in the non-OECD cities.

The share of total annual electricity usage dedicated to thermal comfort provides an indication of where the non-OECD cities may be headed. Of note is the thermal comfort electricity needs (particularly for cooling) of Delhi NDMC, which is as high or higher than many U.S. cities (Fig. 7) and generally represents the largest percentage share of total electricity usage among all cities studied, as shown in Fig. 8. This is likely due to the combination of rapid uptake of air conditioning and an extreme climate (intense heat during the pre-monsoon summer, followed by high heat and humidity throughout the monsoon season). Delhi is still rapidly developing, so it is both an indicator of where the other non-OECD cities in our study may be heading and a warning that the electricity usage we will see in Delhi (and perhaps eventually other cities) in the future may far exceed what OECD cities require for such services.

In general, across all cities surveyed, higher electrical usage was estimated for cooling than for heating, which is likely due to the more widespread use of heating fuels (as opposed to electrical heating) and low heating demands for tropical to subtropical cities.

\subsection{Quantitative Comparison with Previous Studies}

Several previous studies have estimated urban energy requirements for cooling and heating. This section uses two of the most relevant references to as a benchmark for comparison with the results presented in this paper. The selected studies take an entirely different approach from that described in Section 3, and thus provide independent estimates.

Chaturvedi et al [1] simulate building energy demand for India out to 2095. [1] takes a topdown approach, applying national-average data on residential-commercial asset ownership and building square-footage as inputs for a building energy service subroutine [21] of the Global Change Assessment Model [71]. Modeling is performed separately for urban and rural buildings given different baseline conditions and divergent trajectories. Broadly, [1] highlights the same key findings as the current study: Urbanization and demand for building energy services are key drivers of global energy usage.

As a comparison with [1], we estimate annual per capita electricity usage for cooling services to be $434 \mathrm{kWh}$ for the Northeast, East and Central districts of Delhi; $438 \mathrm{kWh}$ in the NW-N districts, $517 \mathrm{kWh}$ in the military cantonment, $569 \mathrm{kWh}$ in the W-SW-S districts, and $1578 \mathrm{kWh} /$ capita/year in New Delhi, the government and VIP area of the city.

Applying cooling appliance ownership, usage and wattage estimates from [1] and scaling by the number of households in Delhi and the average number of people per household [72], we arrive at an estimate of $29 \mathrm{kWh} / \mathrm{capita} /$ year for NCT-Delhi based on the Indiawide estimates of [1]: An order of magnitude lower than our estimates, indicating significantly more electricity use per capita for thermal comfort in NCT-Delhi than the 
country as a whole. This is likely due to both larger conditioned floor areas (both residential and commercial) and higher cooling appliance ownership in Delhi.

We also benchmark our results with that of [22], which presents a family of deterministic equations for estimating final energy usage for building energy services in urban and rural India. Of particular interest from [22] are the estimates of unit energy consumption (UEC) for cooling appliances. They estimate UEC, in units of $\mathrm{kWh} /$ household/year, for electric airconditioning (ac) and evaporative cooling (evap) as follows:

$$
\begin{gathered}
\mathrm{UEC}_{\mathrm{ac}}=\mathrm{CDD} \times\left(0.865 \times \ln \left(\mathrm{Y}_{p p p}\right)-6.04\right) \\
\mathrm{UEC}_{\text {evap }}=\mathrm{UEC}_{\mathrm{ac}} \times \frac{300}{2160}
\end{gathered}
$$

where CDD are cooling degree days with an $18^{\circ} \mathrm{C}$ threshold temperature, and $Y_{p p p}$ are household expenditures adjusted for purchasing power parity.

Following the formula and estimates of [22] for $Y_{p p p}$, CDD and persons per household for Delhi, we arrive at a harmonized estimate of cooling electricity usage of 1853 $\mathrm{kWh} /$ capita/year. This is very similar to our empirical estimate of $1578 \mathrm{kWh} / \mathrm{capita} / \mathrm{year}$ for New Delhi, the government and VIP area of Delhi, despite the need to approximate certain inputs to the formulae of [22]4. Further, there may be underlying electricity demand for cooling spaces year-round (e.g. for data centers or other spaces with very high internal loads) that would not be captured in our analysis.

\section{Conclusion}

This study provides a baseline assessment of urban electricity demand for cooling and heating in 35 global cities - 18 in the OECD and 17 outside the OECD. We estimate the electricity demand for thermal comfort, as a response to ambient temperature, using empirical electricity demand and meteorological data. We derive the threshold temperature between cooling and heating regimes in each city, and suggest using this as a basis for cooling and heating estimates rather than a traditional fixed threshold temperature across all cities in order to better reflect local micro-climates, building stocks, and energy use behaviors. Our results indicate significant difference in cooling electricity requirements of OECD cities (35-90 Watts per ${ }^{\circ} \mathrm{C}$ per capita) and non-OECD cities (2-9

${ }^{4}$ Household expenditure data was not available for Delhi for the year of interest for Delhi, so we used GDP as a proxy. Our value is likely an overestimate because GDP includes household, business and government expenditures. Second, we were unable to extrapolate appliance ownership rates from [22], which reported appliance ownership as a function of household expenditures up to 1500 USD-ppp/capita; the GDP/capita for Delhi is nearly 30,000 USD-ppp/capita [72]. 
Watts $/{ }^{\circ} \mathrm{C} /$ capita); however, the trends observed through our analysis indicate the gradual (and in some cases rapid) adoption of air conditioning equipment in developing cities.

Non-OECD cities in cooling climates likely exhibit lower cooling electricity response than do OECD cities because of low penetration of cooling equipment. Some non-OECD cities (most notably New Delhi) are further along the development spectrum, already use significant amounts of electricity for cooling and heating, and are located in regions that experience very high temperatures. These cities are likely to see significant increases in both annual electricity usage and peak electricity demands for thermal comfort in the future. Delhi already exceeds nearly all OECD cities included in the study and may serve as a harbinger of what is to come in other developing cities; even Delhi is likely to see significant growth in electricity demand for thermal comfort as its cooling electricity response to ambient temperature remains lower than all OECD cities studied.

The reasons for the differences in thermal comfort electricity usage estimates for specific OECD cities can be surmised based on historical development patterns in the U.S. and the urban ecology of the cities as they exist today. This indicates that, though the non-OECDs generally appear fairly early in their adoption of cooling and heating systems, the manner in which those cities develop could have very significant implications for the trajectory of their energy usage.

The results of this study and the analytical approach developed to arrive at those results, provide a strong foundation for further research in urban energy studies. Resource management in rapidly urbanizing areas may prove even more challenging where peak electricity demands are far higher than average demands, and the economic landscape of such an electricity regime may provide either unique opportunities for or particular difficulties in integrating renewable energy resources. Further research is also needed to understand why the cities across our spectrum behave as they do. We have identified factors that may contribute to the energy usage and demands of OECD cities; quantifying these effects could help better project future non-OECD cities' energy requirements and inform urban infrastructure planning in these areas.

\section{Acknowledgements}

We would like to acknowledge the following organizations for their cooperation: Thika Power, Autorite Nationale de Regulation du Secteur d'Electricite, Kenya Power \& Light, Philippine Electricity Market Corporation, Ghana Grid Company, Senelec, Electricite du Liban, National Electric Power Company, Tokyo Electric Power Company and Swaziland Electricity Company, Strategy\& (formerly Booz\&Company). Partial support for this research was provided by the National Science Foundation Sustainability Research Network Award "Integrated Urban Infrastructure Solutions for Environmentally Sustainable, Healthy and Livable Cities" (NSF Award Number 1444745). 


\section{Appendix}

\section{Supplementary material}

All data and analysis used in this study are available online at https://github.com/ecohen4/energy. We encourage readers to fork the repository and contribute to the open-source research community via pull requests.

\begin{tabular}{ll}
\multicolumn{2}{l}{ Delhi DISCOM to District Mapping } \\
DISCOM & Districts \\
\hline NDMC & New Delhi \\
MES & Military \\
BRPL & W-SW-S \\
BYPL & NE-E-Central \\
NDPL & NW-N
\end{tabular}

\section{References}

[1] Chaturvedi V, Eom J, Clarke LE, Shukla PR. 2014. Long term building energy demand for India: Disaggregating end use energy services in an integrated assessment modeling framework. Energy Policy, 64: 226-242.

[2] Gertler P, Shelef O, Wolfram C, Fuchs A. 2013. How pro-poor growth affects the demand for energy. National Bureau of Economic Research. NBER Working Paper No. 19092.

[3] Commoner B. 1972. The Environmental Cost of Economic Growth. in Population, Resources and the Environment. Washington, DC: Government Printing Office.

[4] Stirling A. 2014 Transforming power: Social science and the politics of energy choices. Energy Research and Social Science, 1: 83-95.

[5] Hillman T, Ramaswami A. 2010. Greenhouse gas footprints and energy use benchmarks for eight US cities. Environmental Science and Technology, 44(6):1902-1910.

[6] Kennedy C, Steinberger J, Gasson B, Hansen Y, Hillman T, Havranek M, Pataki D, Phdungsilp A, Ramaswami A, Mendez GV. 2009. Greenhouse Gas Emissions from Global Cities. Environmental Science \& Technology, 43: 7297-7302.

[7] U.S. Environmental Protection Agency (EPA). 2015. eGRID2012 GHG Annual Output Emission Rates. http://www2.epa.gov/energy/egrid

[8] Chavez A, Ramaswami A, Nath D, Guru R, Kumar E. 2012. Implementing trans-boundary infrastructure-based greenhouse gas accounting for Delhi, India: Data availability and methods. Journal of Industrial Ecology, 16(6): 814-828.

[9] Pachauri S, Spreng D. 2004. Energy Use and Energy Access in Relation to Poverty. Economic and Political Weekly, 39(3): 271-278.

[10] Gupta E. 2012. Global Warming and Electricity Demand in the Rapidly Growing City of Delhi: A Semi-Parametric Coefficient Approach, Energy Economics, 34(5): 1407-1421. [11] Gupta E. 2014. The Effect of Development on the Climate Sensitivity of Electricity in India. Discussion Papers in Economics. 
[12] Davis, L.W. and Gertler, P.J. 2015. Contribution of air conditioning adoption to future energy use under global warming. Proceedings of the National Academy of Sciences, 112(19): 5962-5967.

[13] Auffhammer, M. 2011. The Relationship Between Air Conditioning Adoption and Temperature. Report to the U.S. Environmental Protection Agency.

[14] Segal M, Shafer H, Mandel M, Alpert P, Balmor V. 1992. Climatic-related evaluations of the summer peak-hours' electrical load in Israel. Journal of Applied Meteorology, 31: 14921498.

[15] Crowley C, Joutz FL. 2003. Hourly electricity loads: temperature elasticities and climate change. 23rd US Association of Energy Economics North American Conference. [16] Letschert VE, McNeil MA. 2007. Coping with Residential Electricity Demand in India's Future - How Much Can Efficiency Achieve? Lawrence Berkeley National Laboratory. ECEEE 2007 SUMMER STUDY. (LBNL 63199).

[17] Zhao H, Magoules F. 2012. A review of the prediction of building energy consumption. Renewable and Sustainable Energy Reviews, 16(6): 3586-3592.

[18] Tian W. 2013. A review of sensitivity analysis methods in building energy analysis. Renewable and Sustainable Energy Reviews, 20: 411-419.

[19] Fumo N. 2014. A review on the basics of building energy estimation. Renewable and Sustainable Energy Reviews, 31: 53-60.

[20] Suganthi L, Samuel AA. 2012. Energy models for demand forecasting - A review. Renewable and Sustainable Energy Reviews, 16(2): 1223-1240.

[21] Eom J, Clarke L, Kim S, Kyle P, Patel P. 2012. China's building energy demand: Long term implications from a detailed assessment. Energy, 46: 405-419.

[22] van Ruijven BJ, van Vuuren DP, de Vries BJM, Isaac M, van der Sluijs JP, Lucas PL, Balachandra P. 2011. Model projections for household energy use in India. Energy Policy, 39: 7747-7761.

8.

[23] Edmonds J, Reilly J. 1983. A long-term global energy-economic model of carbon dioxide release from fossil fuel use. Energy Economics, 5(2): 74-8

[24] Wigley TML, Raper SCB. 1992. Implications for climate and sea level of revised IPCC emissions scenarios. Nature, 357: 293-300.

[25] Wigley TML, Raper SCB. 2002. Reasons for Larger Warming Projections in the IPCC Third Assessment Report. Climate, 15: 2945-2952.

[26] Wan KKW, Li DHW, Liu D, Lam JC. 2011. Future trends of building heating and cooling loads and energy consumption in different climates. Building and Energy, 46(1): 223-234.

[27] Lam JC, Wan KKW, Lam TNT, Wong SL. 2010a. An analysis of future building energy use in subtropical Hong Kong. Energy, 35: 1482-1490.

[28] Saidur R. 2009. Energy consumption, energy savings, and emission analysis in Malaysian office buildings. Energy Policy, 37(10): 4104-4113.

[29] Shariah A, Shalabi B, Rousan A, Tashtoush B. 1998. Effects of absorptance of external surfaces on heating and cooling loads of residential buildings in Jordan. Energy Conversion and Management, 39(3/4): 273-284.

[30] Eskin N, Türkmen H. 2008. Analysis of Annual Heating and Cooling Energy Requirements for Office Buildings in Different Climates in Turkey. Energy and Buildings, 40(5): 763-773. 
[31] Bluyssen PM, Aries M, van Dommelen P. 2011. Comfort of workers in office buildings: The European HOPE project, Building and Environment, 46: 280-288.

[32] Lam JC, Wan KKW, Wong SL, Lam TNT. 2010b. Long-term trends of heat stress and energy use implications in subtropical climates. Applied Energy, 87(2): 608-612.

[33] Wang X, Chen D, Ren Z. 2010. Assessment of climate change impact on residential building heating and cooling energy requirement in Australia. Building and Environment, 45(7): 1663-1682.

[34] Ouedraogo BI, Levermore GJ, Parkinson JB. 2012. Future energy demand for public buildings in the context of climate change for Burkina Faso. Building and Environment, 49: 270-282.

[35] Frank T. 2011. Climate change impacts on building heating and cooling energy demand in Switzerland. Energy and Buildings, 37: 1175-1185.

[36] Lam TNT, Wan KKW, Wong SL, Lam JC. 2010b. Impact of climate change on commercial sector air conditioning energy consumption in subtropical Hong Kong. Applied Energy, 87(7): 2321-2327.

[37] Radhi H. 2009. Evaluating the potential impact of global warming on the UAE residential buildings - A contribution to reduce the $\mathrm{CO}_{2}$ emissions. Building and Environment, 32(6): 2451-2462.

[38] Delfani S, Karami M, Pasdarshahri H. 2010. The effects of climate change on energy consumption of cooling systems in Tehran. Energy and Buildings, 42: 1952-1957.

[39] Olonscheck M, Holsten A, Kropp J. 2011. Heating and cooling energy demand and related emissions of the German residential building stock under climate change. Energy Policy, 39: 4795-4806.

[40] Wong SL, Wan KKW, Li DHW, Lam JC. 2010. Theoretical and experimental analysis of the energy balance of extensive green roofs. Energy and buildings, 42(6): 959-965. [41] Isaac M, van Vuuren DP. 2009. Modeling global residential sector energy demand for heating and air conditioning in the context of climate change. Energy Policy, 37(2): 507521.

[42] Yau YH, Hasbi S. 2013. A review of climate change impacts on commercial buildings and their technical services in the tropics. Renew Sust Energy Rev, 18: 430-441.

[43] Li DHW, Yang L, Lam JC. 2102. Impact of climate change on energy use in the built environment in different climate zones - A review. Energy, 42(1): 103-112.

[44] Rallapalli SR, Ghosh S. 2012. Forecasting monthly peak demand of electricity in India-A critique. Energy Policy, 46: 516-520.

[45] Jung TY.1993. Ordered logit model for residential electricity demand in Korea. Energy Economics, 15(3): 205-209.

[46] Filippini M. 1999. Swiss residential demand for electricity. Applied Economic Letters, 6(8): 533-538.

[47] Fouquet R. 2014. Long-run demand for energy services: income and price elasticities over two hundred years. Rev Environ Econ Policy, June 2014.

[48] Tiwari P. 2000. Architectural, demographic, and economic causes of electricity consumption in Bombay. Journal of Policy Modelling, 22(1): 81-98.

[49] Filippini M, Pachauri S. 2004. Elasticities of electricity demand in urban Indian households. Energy Policy, 32: 429-436.

[50] The World Bank. 2008. Residential Consumption of Electricity in India: Documentation of Data and Methodology. 
[51] Bose RK, Shukla M. 1999. Elasticities of electricity demand in India. Energy Policy, 27(3): 137-146.

[52] Thatcher MJ. 2007. Modeling changes to electricity demand load duration curves as a consequence of predicted climate change for Australia. Energy, 32: 1647-1659.

[53] ASHRAE. 2014. Guideline 14-2014: Measurement of Energy, Demand, and Water Savings.

[54] Doty S, Turner WC. 2013. Energy Management Handbook, 8th Ed. Fairmont Press, Inc. [55] Krarti M. 2014. Energy Audit of Building Systems: An Engineering Approach, 2nd Ed. Taylor \& Francis Group: Boca Raton, FL.

[56] Quandt RE. 1958. The estimation of the parameters of a linear regression system obeying two separate regimes. Journal of the American Statistical Association, 53(284): 873880.

[57] Bacon DW, Watts DG. 1971. Estimating the transition between two intersecting straight lines. Biometrika, 58(3): 525-534.

[58] Khodadadi A, Asgharian M. 2008. Change-point Problem and Regression: An Annotated Bibliography. Collection of Biostatistics Research Archive. Paper 44. [59] Katipamula S, Reddy TA, Claridge DE. 1994. Development and application of regression models to predict cooling energy consumption in large commercial buildings. Proceedings of the ASME/JSME/JSES International Solar Energy Conference, 299-306. [60] Kissock JK, Reddy TA, Claridge DE. 1998. Ambient-temperature regression analysis for estimating retrofit savings in commercial buildings. Journal of Solar Energy Engineering, 120(3): 168-176.

[61] American Society of Heating, Refrigerating and Air-Conditioning Engineers (ASHRAE). 2013. ASHRAE Handbook - Fundamentals.

[62] Bessec M, Fouquau J. 2008. The non-linear link between electricity consumption and temperature in Europe: A threshold panel approach. Energy Economics, 30(5): 2705-2721. [63] Moral-Carcedo J, Vicens-Otero J. 2005. Modelling the non-linear response of Spanish demand to temperature variations. Energy Economics, 27: 477-494.

[64] Bhattacharyya SC, Timilsina GR. 2009. Energy demand models for policy formulation: a comparative study of energy demand models. Policy Research Working Paper no. WPS 4866.

[65] Craig PP, Gadgil A, Koomey JG. 2002. What can history teach us? A retrospective examination of long-term energy forecasts for the United States, Ann. Rev. Ener Envi., 27: 83-118.

[66] Lovins AB. 1976. Energy strategy: The road not taken. Foreign Affairs, 55(1): 65-96. [67] Armstrong JS. 2001, Principles of Forecasting: A handbook for researchers and practitioners. Norwell, MA: Kluwer Academic.

[68] United Nations. 2014. World Urbanization Prospects - the United Nations. http://esa.un.org/unpd/wup/Highlights/WUP2014-Highlights.pdf. Accessed May 2015. [69] Sailor DJ. 2001. Relating residential and commercial sector electricity loads to climate - evaluating state level sensitivities and vulnerabilities. Energy, 26: 645-657.

[70] R Core Team, R: A language and environment for statistical computing, (2016). http://www.r-project.org/.

[71] Edmonds J, Wise M, Pitcher H, Richels R, Wigley T, and MacCracken C. 1997. An Integrated Assessment of Climate Change and the Accelerated Introduction of Advanced Energy Technologies, Mitigation and Adaptation Strategies for Global Change, 1: 311-39. 
[72] Delhi Statistical Abstract 2012. 2012.

http://delhi.gov.in/DoIT/DES/Publication/abstract/SA2012.pdf. Accessed May 2015. [73] DES (Directorate of Economics and Statistics). 2009. Directorate of Economics and Statistics. www.delhi.gov.in/wps/wcm/connect/DOIT_DES/des/home/. Accessed March 2011.

[74] NOAA (National Oceanic and Atmospheric Administration). 2014. http://www.noaa.gov/. Accessed December 2014.

[75] NSCB (National Statistical Coordination Board - Philippine Statistics Authority). 2015. http://www.nscb.gov.ph/secstat/d_popn.asp. Accessed May 2015.

[76] US Census Bureau. 2014. Population Estimates. http://www.census.gov/popest/data/index.html. Accessed May 2015.

[77] PJM (PJM Interconnection LLC). 2014. Energy Market. http://www.pjm.com/marketsand-operations/energy.aspx. Accessed October 2014.

[78] FERC (Federal Electricity Regulatory Commission). 2014. Form No. 714 - Annual Electric Balancing Authority Area and Planning Area Report.http://www.ferc.gov/docsfiling/forms/form-714/data.asp. Accessed May 2015.

[79] EIA (U.S. Energy Information Administration). 2015. Electricity Power Monthly. http://www.eia.gov/ electricity/monthly/index.cfm. Accessed May 2015. 


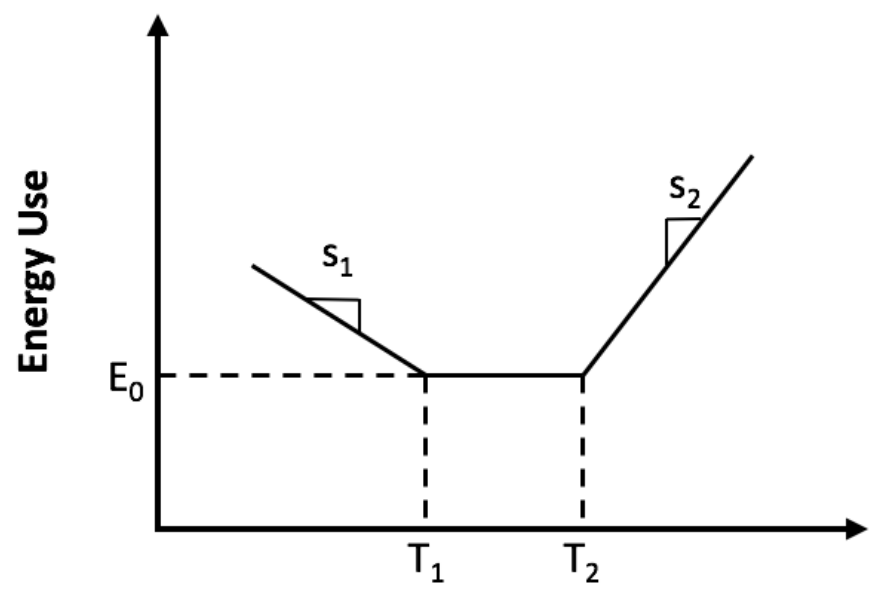

Ambient Temperature

Fig. 1. Five-parameter change-point regression Model
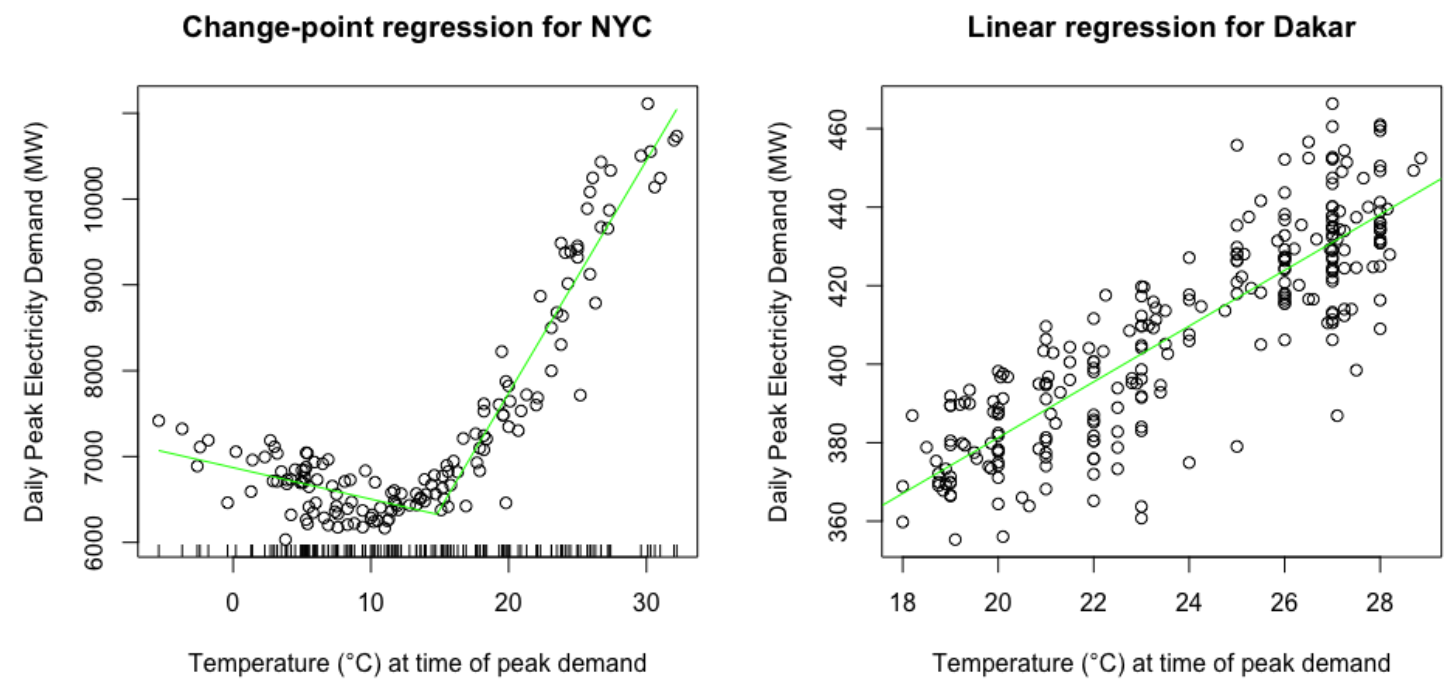

Fig. 2. Temperature-Load Curves: (a) 2012 change-point regression model for New York City and (b) 2012 linear regression model for Dakar 

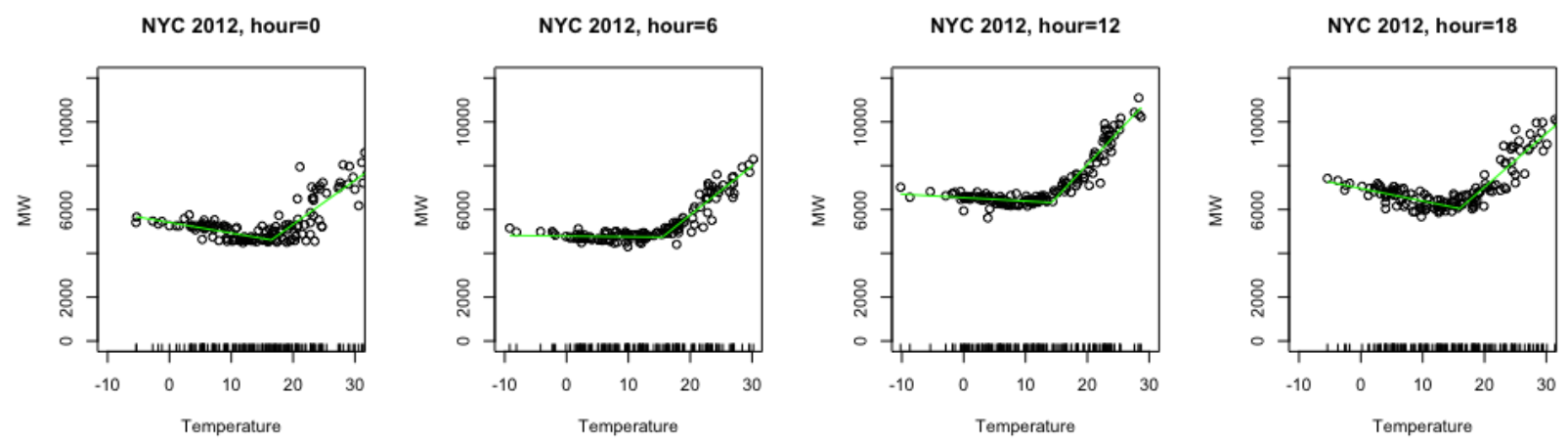

Fig. 3. Temperature-Load Curves and change-point regression models for New York City, 2012 at midnight, $6 \mathrm{am}, 12 \mathrm{pm}$ and $6 \mathrm{pm}$
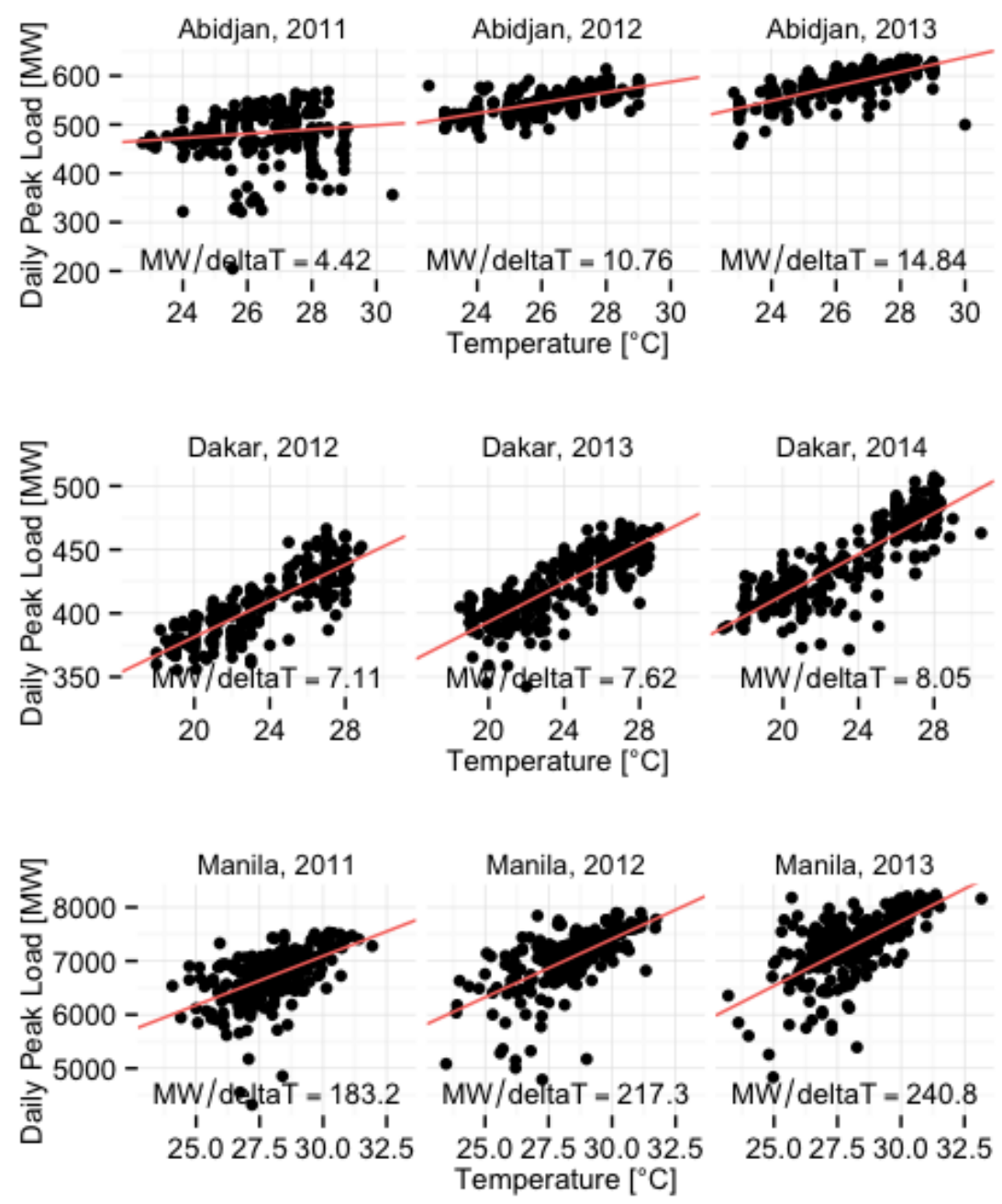

Fig. 4. Observed growth in cooling electricity response for example tropical/subtropical cities. 


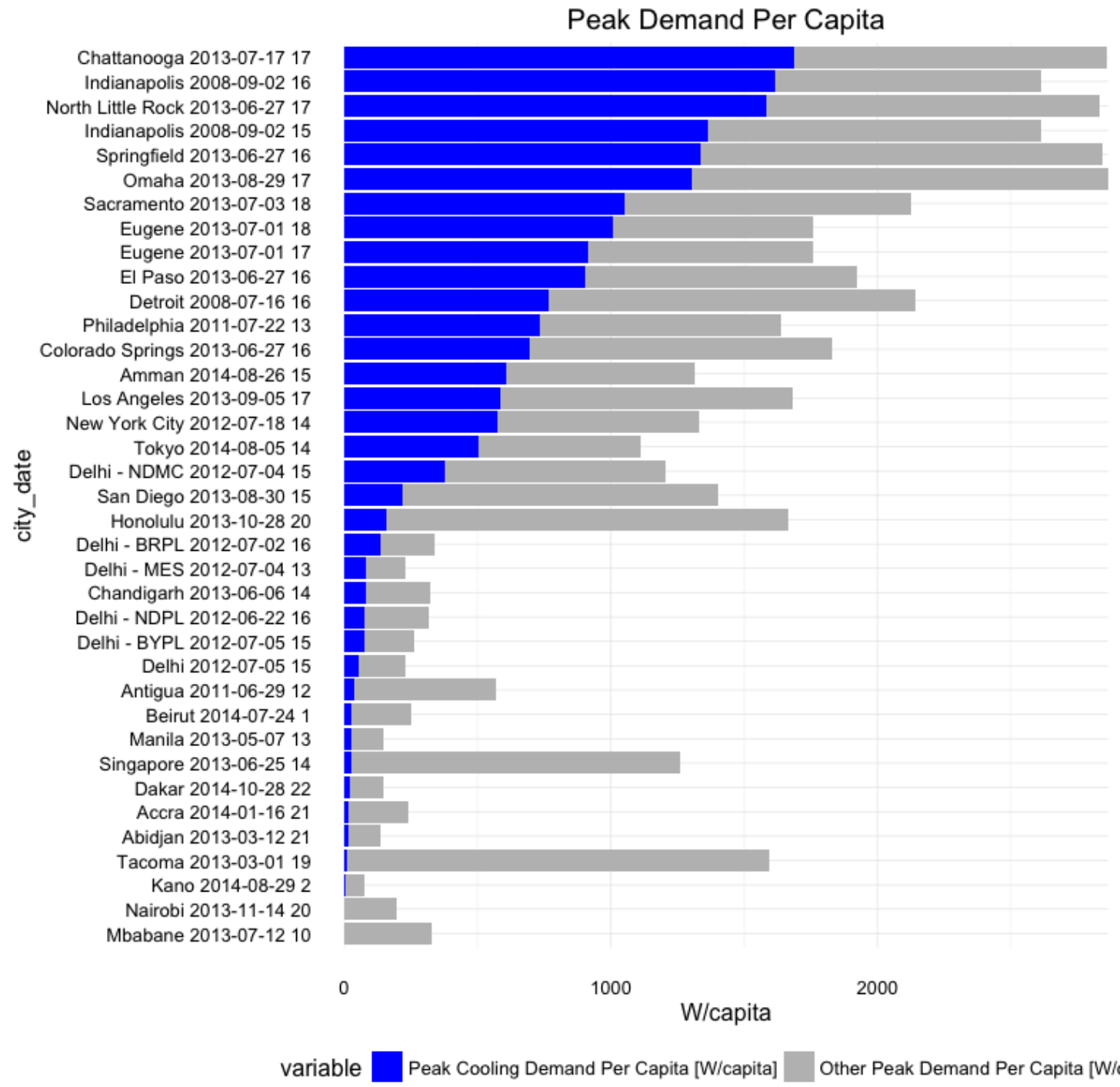

Fig. 5 Per capita peak electricity demand and estimated contribution from cooling. 


\section{Fraction of Peak Demand Per Capita}

Indianapolis 2008-09-02 16 Chattanooga 2013-07-17 17 Eugene 2013-07-01 18 North Little Rock 2013-06-27 17

Indianapolis 2008-09-02 15 Eugene 2013-07-01 17

Sacramento 2013-07-03 18

El Paso 2013-06-27 16

Springfield 2013-06-27 16

Amman 2014-08-26 15

Omaha 2013-08-29 17

Tokyo 2014-08-05 14

Philadelphia 2011-07-22 13

New York City 2012-07-18 14

Delhi - BRPL 2012-07-02 16

Colorado Springs 2013-06-27 16

Detroit 2008-07-16 16

胥 Delhi - MES 2012-07-04 13

I) Los Angeles 2013-09-05 17

능 Delhi - NDMC 2012-07-04 15

Delhi - BYPL 2012-07-05 15

Chandigarh 2013-06-06 14 Delhi 2012-07-05 15

Delhi - NDPL 2012-06-22 16

Manila 2013-05-07 13

Dakar 2014-10-28 22

San Diego 2013-08-30 15

Abidjan 2013-03-12 21

Beirut 2014-07-24 1

Honolulu 2013-10-28 20

Kano 2014-08-29 2

Accra 2014-01-16 21

Antigua 2011-06-29 12

Singapore 2013-06-25 14

Tacoma 2013-03-01 19

Nairobi 2013-11-14 20

Mbabane 2013-07-12 10

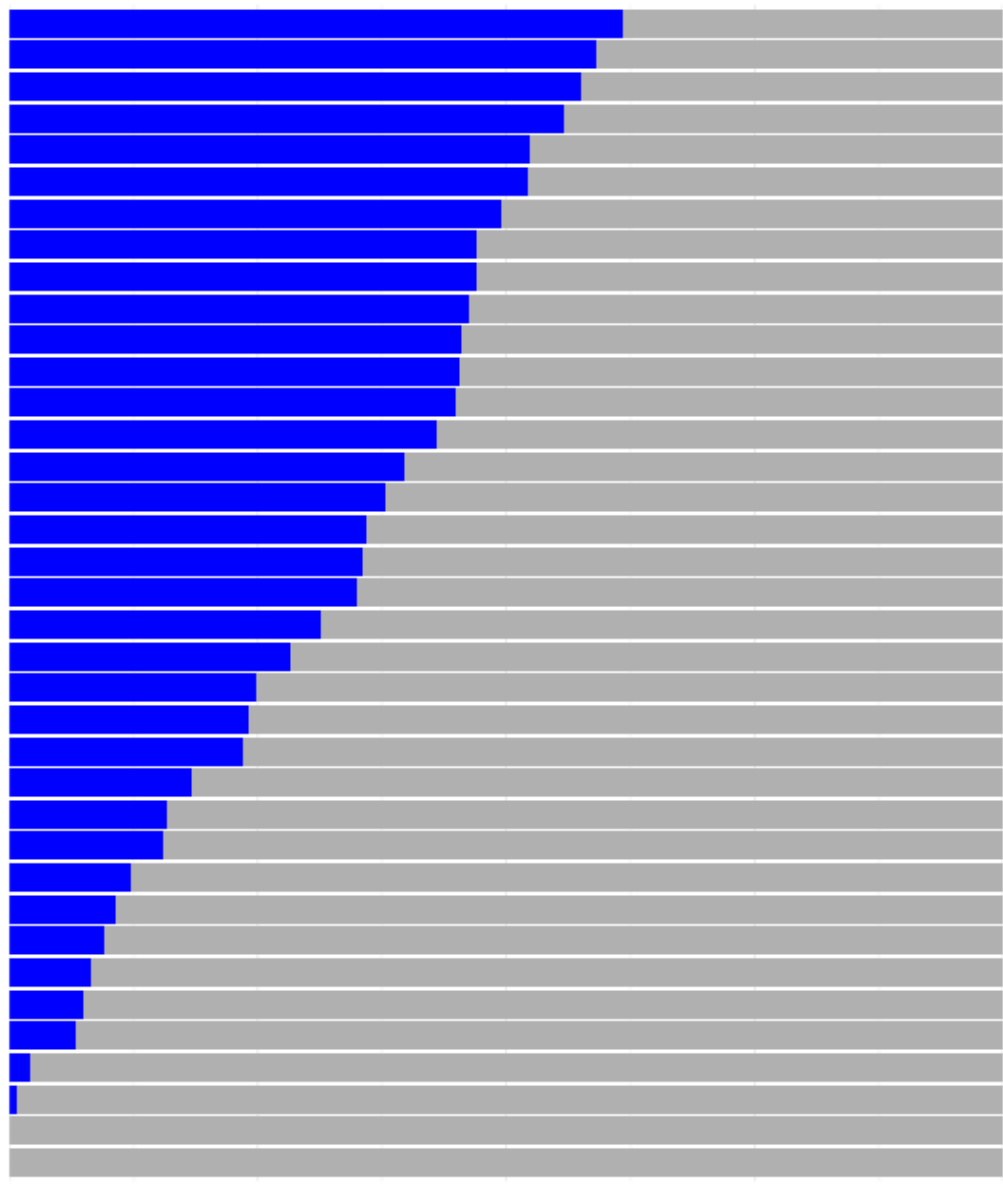

25

50

75

$10 \mathrm{C}$

variable

$\%$ Demand for Cooling Per Capita

Other Peak Demand Per Capita (\%)

Fig. 6 Per capita cooling electricity demand as percent contribution to peak demand 


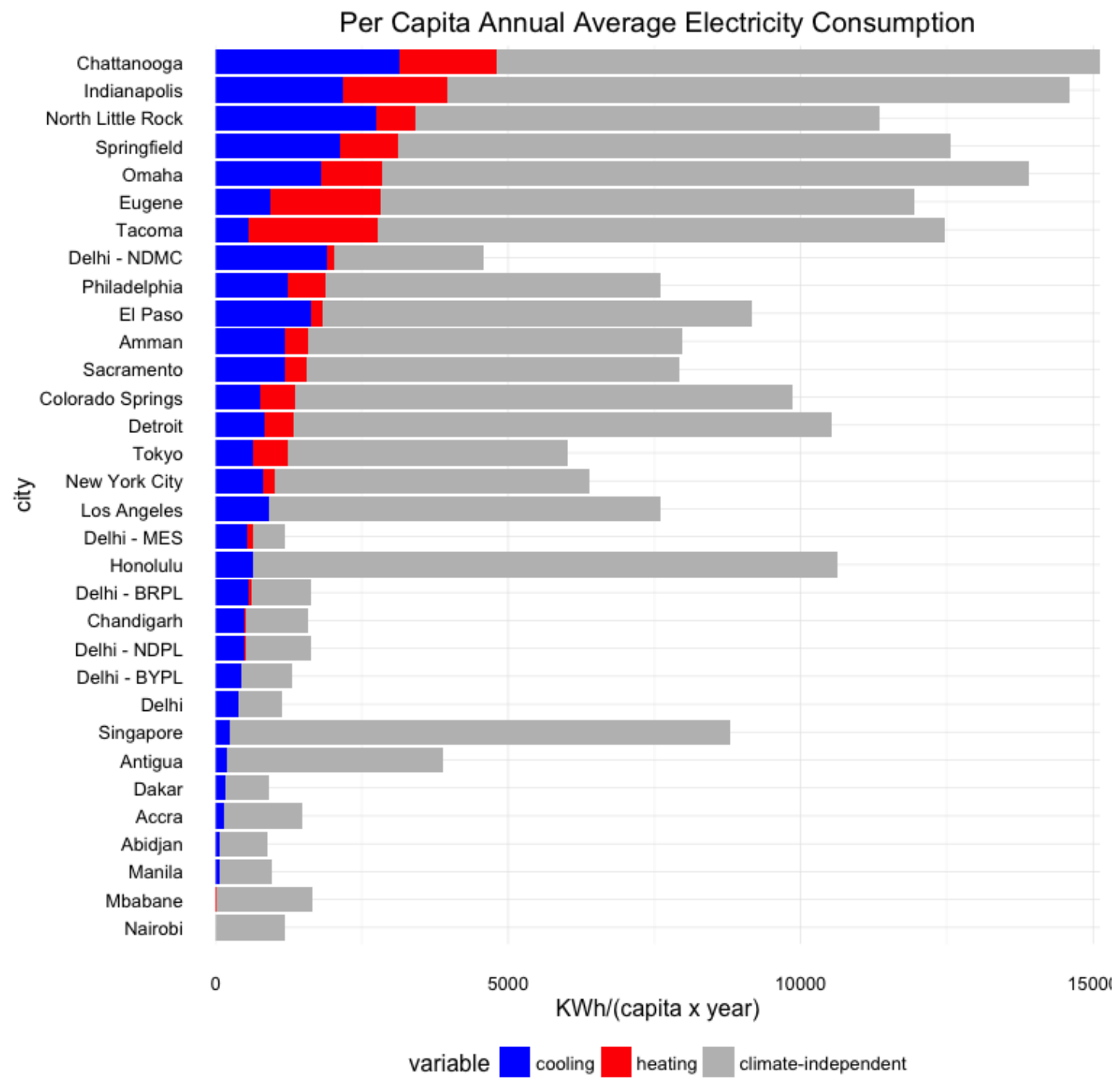

Fig. 7 Annual average per capita electricity usage for cooling and heating, compared to total electricity usage. 


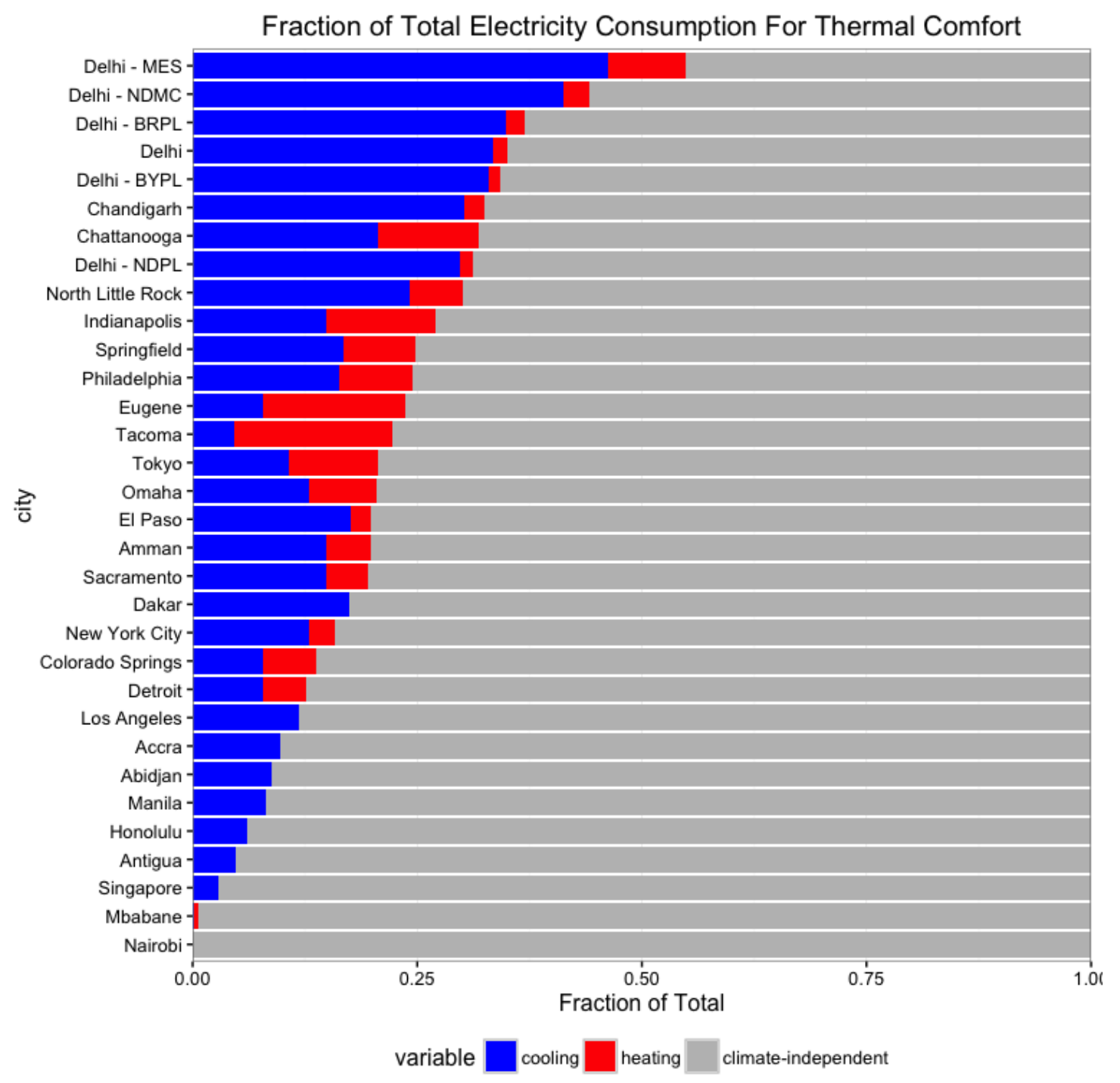

Fig. 8 Electricity usage for cooling and heating as fraction of total electricity usage. 


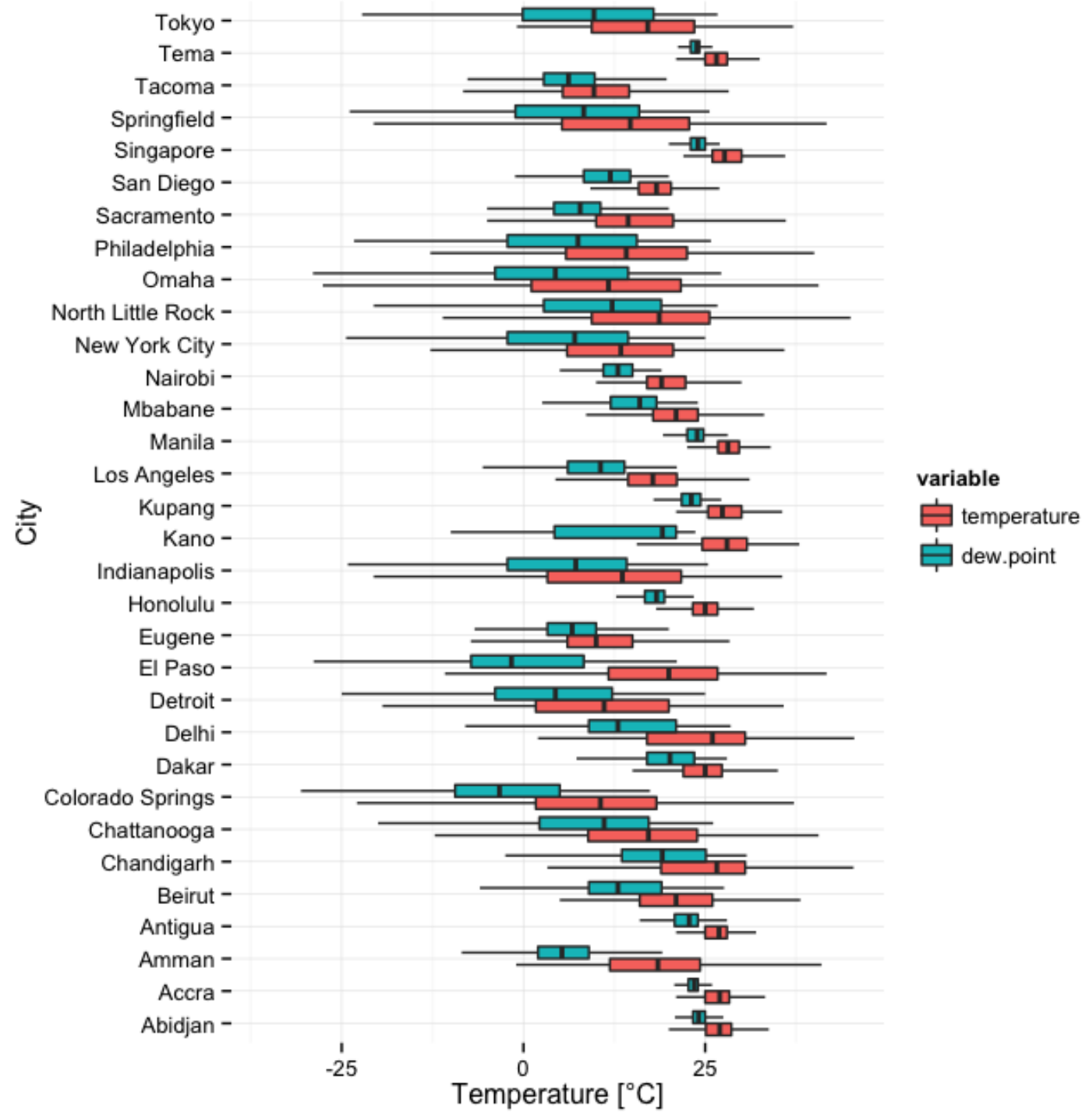

Fig. A1. Temperature and dew point variation by city. Boxes show interquartile range (with vertical line indicating mean value); horizontal lines indicate full range of data. 
Table 1. Per-capita peak electricity response for cooling and heating in $\mathrm{W} /\left({ }^{\circ} \mathrm{C} \mathrm{x}\right.$ capita). Minimum and maximum values given for the range of years analyzed for each city.

\begin{tabular}{|c|c|c|c|c|c|}
\hline \multirow[t]{2}{*}{ City } & \multirow[t]{2}{*}{ Year Range } & \multicolumn{2}{|c|}{$\begin{array}{l}\text { Heating Electricity Response } \\
\left(\mathrm{W} /{ }^{\circ} \mathrm{C} / \text { capita }\right)\end{array}$} & \multicolumn{2}{|c|}{$\begin{array}{c}\text { Cooling Electricity Response } \\
\left(\mathrm{W} /{ }^{\circ} \mathrm{C} / \text { capita) }\right.\end{array}$} \\
\hline & & Minimum & Maximum & Minimum & Maximum \\
\hline Abidjan & $2010-2013$ & 0 & 0 & 0 & 3.23 \\
\hline Accra & $2013-2014$ & 0 & 0 & 1.69 & 3.97 \\
\hline Amman & 2011-2014 & 25.7 & 30.6 & 44.9 & 47.4 \\
\hline Antigua & 2011 & \multicolumn{2}{|c|}{0} & \multicolumn{2}{|c|}{6.74} \\
\hline Beirut & 2011-2014 & 0 & 1.21 & 3.74 & 5.53 \\
\hline Chandigarh & 2011-2013 & 0 & 3.99 & 8.6 & 11.4 \\
\hline Chattanooga & $2006-2013$ & 32.0 & 60.5 & 128 & 151 \\
\hline Colorado Springs & $2006-2013$ & 4.56 & 11.69 & 29.6 & 50.3 \\
\hline Dakar & 2011-2014 & 0 & 0 & 2.04 & 2.35 \\
\hline Delhi & 2011-2012 & 0 & 0 & 4.36 & 5.72 \\
\hline Delhi - BRPL & 2011-2012 & 0 & 1.98 & 9.08 & 11.9 \\
\hline Delhi - BYPL & 2011-2012 & 0 & 0 & 5.84 & 6.59 \\
\hline Delhi - MES & $2011-2012$ & 6.84 & 7.26 & 9.11 & 9.26 \\
\hline Delhi - NDMC & $2011-2012$ & 0 & 0 & 39.4 & 39.9 \\
\hline Delhi - NDPL & 2011-2012 & 0 & 1.53 & 5.54 & 7.26 \\
\hline Detroit & $2006-2008$ & 3.74 & 6.77 & 59.5 & 72.3 \\
\hline El Paso & $2006-2013$ & 0 & 8.27 & 41.4 & 66.2 \\
\hline Eugene & $2006-2013$ & 44.5 & 60.4 & 53.0 & 72.1 \\
\hline Honolulu & $2006-2013$ & 0 & 0 & 6.91 & 21.7 \\
\hline Indianapolis & $2006-2008$ & 21.3 & 31.6 & 92.5 & 99.3 \\
\hline Kano & 2013 & \multicolumn{2}{|c|}{0} & \multicolumn{2}{|c|}{0.5} \\
\hline Los Angeles & $2006-2013$ & 0 & 0 & 24.8 & 42.2 \\
\hline Manila & $2011-2013$ & 0 & 0 & 3.37 & 4.28 \\
\hline Mbabane & 2013 & \multicolumn{2}{|c|}{3.64} & \multicolumn{2}{|c|}{0} \\
\hline Nairobi & 2011-2013 & 0 & 1.13 & 0 & 0 \\
\hline New York City & $2007-2013$ & 3.34 & 6.46 & 34.1 & 39.4 \\
\hline North Little Rock & $2010-2013$ & 3.98 & 7.4 & 113 & 128 \\
\hline Omaha & $2006-2013$ & 7.75 & 15.8 & 89.7 & 113 \\
\hline Philadelphia & $2009-2011$ & 3.74 & 3.97 & 57.2 & 60.3 \\
\hline Sacramento & $2006-2013$ & 0 & 14.2 & 78.8 & 92.4 \\
\hline San Diego & $2012-2013$ & 0 & 0 & 14.9 & 21.4 \\
\hline Singapore & 2013 & \multicolumn{2}{|c|}{0} & \multicolumn{2}{|c|}{13.34} \\
\hline Springfield, IL & 2011-2013 & 4.09 & 12.9 & 102 & 125 \\
\hline Tacoma & $2006-2013$ & 42.1 & 47.7 & 44.8 & 52.8 \\
\hline Tokyo & $2008-2014$ & 11.5 & 24.8 & 41.3 & 53.7 \\
\hline
\end{tabular}


Table A1. Data sources summary

\begin{tabular}{|c|c|c|c|c|}
\hline City & Country & Load & Weather & Population \\
\hline Abidjan & Cote d'Ivoire & 2010-2013 (a) & $2010-2013(\mathrm{l})$ & $1990-2030(\mathrm{~m})$ \\
\hline Accra & Ghana & 2013-2014 (b) & 2010-2013 (l) & $1990-2030(\mathrm{~m})$ \\
\hline Amman & Jordan & 2011-2014 (c) & 2010-2013 (l) & $1990-2030(\mathrm{~m})$ \\
\hline Antigua & Antigua and Barbuda & $2011-2011(d)$ & $2010-2013(\mathrm{l})$ & \\
\hline Beirut & Lebanon & 2011-2014 (e) & 2010-2013 (l) & $1990-2030(\mathrm{~m})$ \\
\hline Chandigarh & India & $2011-2013$ (d) & 2010-2013 (l) & $1990-2030(\mathrm{~m})$ \\
\hline Chattanooga & U.S. & 2006-2013 (r) & 2006-2013 (l) & $2006-2013(\mathrm{~s})$ \\
\hline Colorado Springs & U.S. & 2006-2013 (r) & 2006-2013 (l) & $2006-2013(\mathrm{~s})$ \\
\hline Dakar & Senegal & 2011-2014 (f) & 2010-2013 (l) & $1990-2030(\mathrm{~m})$ \\
\hline Delhi & India & 2012-2013 (e) & 2010-2013 (l) & $1990-2030(\mathrm{~m})$ \\
\hline Detroit & U.S. & 2006-2008 (r) & 2006-2008 (l) & 2006-2008 (s) \\
\hline El Paso & U.S. & 2006-2013 (r) & 2006-2013 (l) & $2006-2013$ (s) \\
\hline Eugene & U.S. & 2006-2013 (r) & 2006-2013 (l) & $2006-2013(\mathrm{~s})$ \\
\hline Honolulu & U.S. & 2006-2013 (r) & 2006-2013 (l) & $2006-2013$ (s) \\
\hline Indianapolis & U.S. & 2006-2008 (r) & 2006-2008 (l) & $2006-2008(\mathrm{~s})$ \\
\hline Kano & Nigeria & $2014(d)$ & 2014 (l) & $1990-2030(\mathrm{~m})$ \\
\hline Kupang & Indonesia & $2013(d)$ & $2013(1)$ & 2011 (o) \\
\hline Los Angeles & U.S. & 2006-2013 (r) & 2006-2013 (l) & $2006-2013(\mathrm{~s})$ \\
\hline Manila & Philippines & 2011-2013 (g) & 2010-2013 (l) & $2010-2015(\mathrm{n})$ \\
\hline Mbabane & Swaziland & 2012-2014 (h) & 2010-2013 (l) & 2010 (o) \\
\hline Nairobi & Kenya & 2011-2013 (i) & 2010-2013 (l) & $1990-2030(\mathrm{~m})$ \\
\hline New York City & U.S. & $2007-2012(d)$ & 2007-2012 (l) & $2007-2012(\mathrm{p})$ \\
\hline N. Little Rock & U.S. & $2010-2013$ (r) & 2010-2013 (l) & $2010-2013(\mathrm{~s})$ \\
\hline Omaha & U.S. & 2006-2013 (r) & 2006-2013 (l) & $2006-2013(\mathrm{~s})$ \\
\hline Philadelphia & U.S. & $2009-2011(q)$ & 2009-2011 (l) & $1990-2030(\mathrm{~m})$ \\
\hline Sacramento & U.S. & 2006-2013 (r) & 2006-2013 (l) & 2006-2013 (s) \\
\hline San Diego & U.S. & $2012-2013$ (r) & 2012-2013 (l) & $2012-2013$ (s) \\
\hline Singapore & Singapore & $2013-2013(j)$ & 2010-2013 (l) & $1990-2030(\mathrm{~m})$ \\
\hline Springfield, IL & U.S. & 2011-2013 (r) & 2011-2013 (l) & 2011-2013 (s) \\
\hline Tacoma & U.S. & 2006-2013 (r) & 2006-2013 (l) & $2006-2013$ (s) \\
\hline Tokyo & Japan & 2008-2014 (k) & 2010-2013 (l) & 2008-2014 (k) \\
\hline
\end{tabular}

Personal Communications: (a): Autorite Nationale de Regulation du Secteur de l'Electricite, (b) Ghana Grid Company, (c) National Electric Power Company, (d) Sustainable Engineering Lab, (e) Electricite Du Liban, (f) Senelec, (g) Philipine Electricity Market Corporation, (h) Swaziland Electricity Company, (i) Kenya Power and Lighting Company, (j) Energy Market Authority, (k) Tokyo Electric Power Company; (l) NOAA 2014 [74]; (m) World Urbanization Prospects - 2014 [68]; (n) NSCB 2015 [75]; (o) UN Data [9]; (p) US Census Bureau [76]; (q) PJM [77]; (r) FERC [78]; (s) EIA [79] 
Table A2. Per capita cooling electricity response and electricity usage for cooling by city (average of all years). Cities listed in ascending order by cooling response.

\begin{tabular}{|c|c|c|c|}
\hline City & $\begin{array}{c}\text { Threshold } \\
\text { Temperature }\end{array}$ & $\begin{array}{c}\text { Cooling Electricity } \\
\text { Response } \\
\mathrm{W} /\left({ }^{\circ} \mathrm{C} \text {-capita }\right)\end{array}$ & $\begin{array}{l}\text { Estimated Cooling } \\
\text { Electricity Usage } \\
\text { kWh/(capita-yr) }\end{array}$ \\
\hline Mbabane & 13 & 0 & 4.09 \\
\hline Nairobi & 14 & 0 & 0 \\
\hline Kano & 15 & 0.5 & (a) \\
\hline Abidjan & 23 & 1.67 & 53 \\
\hline Dakar & 19 & 2.23 & 145 \\
\hline Accra & 24 & 2.83 & 144 \\
\hline Manila & 25 & 3.86 & 69.8 \\
\hline Beirut & 22 & 4.45 & (a) \\
\hline Delhi & 21 & 5.04 & 370 \\
\hline Delhi - BYPL & 21 & 6.22 & 434 \\
\hline Delhi - NDPL & 22 & 6.4 & 438 \\
\hline Antigua & 23 & 6.74 & 188 \\
\hline Delhi - MES & 25 & 9.19 & 517 \\
\hline Chandigarh & 20 & 9.6 & 478 \\
\hline Delhi - BRPL & 22 & 10.49 & 569 \\
\hline Singapore & 25 & 13.34 & 246 \\
\hline Honolulu & 21 & 13.8 & 662 \\
\hline San Diego & 12 & 18.15 & (a) \\
\hline Los Angeles & 12 & 31.33 & 876 \\
\hline New York City & 15 & 37.23 & 861 \\
\hline Delhi - NDMC & 22 & 39.61 & 1579 \\
\hline Colorado Springs & 17 & 40.39 & 628 \\
\hline Amman & 18 & 45.72 & 1257 \\
\hline Tokyo & 18 & 46.81 & 718 \\
\hline Tacoma & 14 & 49.2 & 537 \\
\hline El Paso & 19 & 52.56 & 1481 \\
\hline Philadelphia & 21 & 58.5 & 1186 \\
\hline Eugene & 12 & 64.95 & 737 \\
\hline Detroit & 18 & 67.36 & 894 \\
\hline Sacramento & 20 & 87.21 & 1100 \\
\hline Indianapolis & 16 & 94.96 & 2194 \\
\hline Omaha & 19 & 100.9 & 1880 \\
\hline Springfield, IL & 20 & 109.9 & 2334 \\
\hline North Little Rock & 22 & 120.6 & 2927 \\
\hline
\end{tabular}




\begin{tabular}{cccc} 
City & $\begin{array}{c}\text { Threshold } \\
\text { Temperature }\end{array}$ & $\begin{array}{c}\text { Cooling Electricity } \\
\text { Response } \\
\text { W/ } /\left({ }^{\circ} \mathrm{C}-\text { capita }\right)\end{array}$ & $\begin{array}{c}\text { Estimated Cooling } \\
\text { Electricity Usage } \\
\text { kWh/(capita-yr) }\end{array}$ \\
\hline Chattanooga & 18 & 141 & 3783 \\
\hline
\end{tabular}

(a) Cooling electricity usage estimates not possible for cities without both cooling and heating responses

Table A3: Timing and magnitude of peak electricity demand and estimated contribution from cooling. Cities listed in ascending order by contribution of cooling to overall peak electricity demand.

\begin{tabular}{|c|c|c|c|c|c|c|}
\hline City & Date & Hour & $\begin{array}{c}\text { Temperature } \\
\left({ }^{\circ} \mathrm{C}\right)\end{array}$ & $\begin{array}{l}\text { Peak Elec. } \\
\text { Demand } \\
(\mathrm{MW})\end{array}$ & $\begin{array}{l}\text { Estimated Peak } \\
\text { Cooling } \\
\text { Demand (MW) }\end{array}$ & $\begin{array}{l}\% \text { Peak } \\
\text { Demand for } \\
\text { Cooling }\end{array}$ \\
\hline Mbabane & 2013-07-12 & 10 & 19 & 21.83 & 0 & 0 \\
\hline Nairobi & $2013-11-14$ & 20 & 27 & 724.4 & 0 & 0 \\
\hline Tacoma & 2013-03-01 & 19 & 14.2 & 640 & 4.24 & 0.66 \\
\hline Singapore & $2013-06-25$ & 14 & 27 & 6804 & 144.3 & 2.12 \\
\hline Antigua & 2011-06-29 & 12 & 29 & 50.75 & 3.38 & 6.66 \\
\hline Accra & 2014-01-16 & 21 & 28.5 & 541.4 & 39.97 & 7.38 \\
\hline Kano & 2014-08-29 & 2 & 27.14 & 267 & 21.86 & 8.19 \\
\hline Honolulu & $2013-10-28$ & 20 & 29.4 & 1162 & 111.8 & 9.62 \\
\hline Beirut & 2014-07-24 & 1 & 26 & 553.2 & 59.4 & 10.74 \\
\hline Abidjan & 2013-03-12 & 21 & 28.2 & 635.3 & 77.17 & 12.15 \\
\hline San Diego & 2013-08-30 & 15 & 25.6 & 4604 & 711 & 15.44 \\
\hline Dakar & $2014-10-28$ & 22 & 28 & 507.2 & 80.49 & 15.87 \\
\hline Manila & 2013-05-07 & 13 & 31.37 & 8237 & 1509 & 18.32 \\
\hline Delhi - NDPL & $2012-06-22$ & 16 & 36.5 & 1481 & 349.1 & 23.57 \\
\hline Delhi & 2012-07-05 & 15 & 34 & 5360 & 1290 & 24.07 \\
\hline Chandigarh & 2013-06-06 & 14 & 28.27 & 352 & 87.49 & 24.86 \\
\hline Delhi - BYPL & 2012-07-05 & 15 & 34 & 1269 & 359.8 & 28.36 \\
\hline Delhi - NDMC & 2012-07-04 & 15 & 32 & 351.6 & 110.1 & 31.32 \\
\hline Los Angeles & 2013-09-05 & 17 & 32.2 & 5862 & 2049 & 34.96 \\
\hline Delhi - MES & 2012-07-04 & 13 & 34 & 44.61 & 15.89 & 35.62 \\
\hline Detroit & $2008-07-16$ & 16 & 30 & 11011 & 3957 & 35.93 \\
\hline Colorado Springs & $2013-06-27$ & 16 & 33.3 & 883 & 334.4 & 37.87 \\
\hline Delhi - BRPL & 2012-07-02 & 16 & 36.5 & 2311 & 920.7 & 39.85 \\
\hline Philadelphia & 2011-07-22 & 13 & 33.7 & 8984 & 4027 & 44.83 \\
\hline Tokyo & 2014-08-05 & 14 & 29.4 & 49800 & 22552 & 45.28 \\
\hline New York City & 2012-07-18 & 14 & 30.1 & 11112 & 5043 & 45.38 \\
\hline Omaha & 2013-08-29 & 17 & 33.9 & 2351 & 1070 & 45.52 \\
\hline Amman & $2014-08-26$ & 15 & 31 & 1507 & 697 & 46.27 \\
\hline El Paso & $2013-06-27$ & 16 & 33.3 & 1750 & 822.7 & 47.01 \\
\hline
\end{tabular}




\begin{tabular}{ccccccc} 
City & Date & Hour & $\begin{array}{c}\text { Temperature } \\
\left({ }^{\circ} \mathrm{C}\right)\end{array}$ & $\begin{array}{c}\text { Peak Elec. } \\
\text { Demand } \\
(\mathrm{MW})\end{array}$ & $\begin{array}{c}\text { Estimated Peak } \\
\text { Cooling } \\
\text { Demand (MW) }\end{array}$ & $\begin{array}{c}\text { \%emak Peand for } \\
\text { Cooling }\end{array}$ \\
\hline Springfield, IL & $2013-06-27$ & 16 & 32.8 & 721 & 339.2 & 47.05 \\
Sacramento & $2013-07-03$ & 18 & 33.3 & 3014 & 1493 & 49.54 \\
North Little Rock & $2013-06-27$ & 17 & 35 & 249 & 139 & 55.84 \\
Eugene & $2013-07-01$ & 18 & 26.95 & 366 & 210.5 & 57.5 \\
Chattanooga & $2013-07-17$ & 17 & 32.8 & 1115 & 658.4 & 59.05 \\
Indianapolis & $2008-09-02$ & 16 & 31.7 & 2858 & 1766 & 61.79 \\
\hline
\end{tabular}

Table A4. Per capita heating electricity response and estimated electricity usage for heating by city (average of all years). Cities listed in ascending order by heating response.

\begin{tabular}{cccc} 
City & $\begin{array}{c}\text { Threshold } \\
\text { Temperature }\end{array}$ & $\begin{array}{c}\text { Heating Electricity } \\
\text { Response } \\
\text { W/ }\left({ }^{\circ} \text { C } \text { Capita }\right)\end{array}$ & $\begin{array}{c}\text { Estimated Heating } \\
\text { Electricity Usage } \\
\text { kWh/(capita x yr) }\end{array}$ \\
\hline Abidjan & 23 & 0 & 0 \\
Accra & 24 & 0 & 0 \\
Antigua & 23 & 0 & 0 \\
Dakar & 19 & 0 & 0 \\
Kano & 15 & 0 & 0 \\
Honolulu & 21 & 0 & 0 \\
Manila & 25 & 0 & 0 \\
San Diego & 12 & 0 & 0 \\
Singapore & 25 & 0 & 0 \\
Los Angeles & 12 & 0 & 10.1 \\
Delhi - BYPL & 21 & 0 & 17.7 \\
Delhi & 21 & 0 & 18.8 \\
Delhi - NDMC & 22 & 0 & 93.5 \\
Beirut & 22 & 0.3 & $(\mathrm{a})$ \\
Nairobi & 14 & 0.38 & 0.25 \\
Delhi - NDPL & 22 & 0.77 & 21.1 \\
Delhi - BRPL & 22 & 0.99 & 31.5 \\
El Paso & 19 & 2 & 134 \\
Chandigarh & 20 & 2.12 & 36.1 \\
Mbabane & 13 & 3.64 & 8.48 \\
New York City & 15 & 4.61 & 205 \\
Detroit & 18 & 5.66 & 447 \\
North Little Rock & 22 & 5.8 & 529 \\
Delhi - MES & 25 & 7.05 & 97.3 \\
Sacramento & 20 & 7.75 & 321 \\
& & &
\end{tabular}




\begin{tabular}{cccc} 
City & $\begin{array}{c}\text { Threshold } \\
\text { Temperature }\end{array}$ & $\begin{array}{c}\text { Heating Electricity } \\
\text { Response } \\
\text { W/ }\left({ }^{\circ} \text { C x Capita }\right)\end{array}$ & $\begin{array}{c}\text { Estimated Heating } \\
\text { Electricity Usage } \\
\text { kWh/(capita x yr })\end{array}$ \\
\hline Colorado Springs & 17 & 7.76 & 497 \\
Springfield, IL & 20 & 8.54 & 833 \\
Omaha & 19 & 10.76 & 941 \\
Philadelphia & 21 & 11.11 & 676 \\
Tokyo & 18 & 16.18 & 570 \\
Indianapolis & 16 & 28.02 & 1535 \\
Amman & 18 & 28.3 & 470 \\
Chattanooga & 18 & 44.63 & 1618 \\
Tacoma & 14 & 45.09 & 2113 \\
Eugene & 12 & 53.29 & 1674 \\
\hline
\end{tabular}

(a) Heating electricity usage estimates not possible for cities without both cooling and heating responses 